\title{
Study of Effects of Tiophanate methyl and Carbendazim Fungicides on Paper Structure by Application of Fourier Transform Infrared Spectroscopy
}

\author{
Mahboob Abdolalizadeh ${ }^{1}$, M ehrnaz Azad-Boyaghchi ${ }^{2}$, Mohsen \\ Mohammadi-Achachlouei ${ }^{3}$, Rana Bahremandi-Poorfard ${ }^{4}$ \\ ${ }^{1}$ M.A., Faculty of Conservation \& Restoration, Art University of Isfahan, Isfahan, IRAN \\ ${ }^{2,3}$ Assistant Professor, Faculty of Conservation \& Restoration, Art University of Isfahan, Isfahan, IRAN \\ ${ }^{4}$ M.A. Department of Archaeometry, Faculty of Applied Arts, Tabriz Islamic Art University, Tabriz, IRAN
}

\begin{abstract}
Most of fungicides for prevention of biological degradation in historic papers, firstly have been used in the other scientific and industrial fields such as material preservation, agriculture and medical science. Other scientific fields have a great importance in the conservation of historic relics especially paper relics. Therefore, Tiophanate methyl and Carbendazim fungicides were studied for application in the conservation and restoration of paper relics. Each of these materials is one of most important and applied materials in agriculture which are effective against wide range of biological factors. Conservation material should not have intensive structural effects on paper relics. Accordingly, it is required to evaluate effects of Tiophanate methyl and Carbendazim treatments on paper. Fourier Transform Infrared Spectroscopy (FTIR) is one of most important methods for structural changes of paper. For the study, laboratory samples were prepared from filter paper. Samples were treated with Tiophanate methyl (dissolved in methanol) and Carbendazim (dissolved in distilled water) in $100 \mathrm{ppm}$ and $200 \mathrm{ppm}$ concentrations by spray method. Blank and treated samples were aged according to ISIRI4706 standard method for 288 hours. After aging, structural changes have been studied by application of Fourier Transform Infrared Spectroscopy. Results showed that spectra of treated paper samples with Tiophanate methyl and Carbendazim have no structural deformation in both $100 \mathrm{ppm}$ and $200 \mathrm{ppm}$ concentrations. According to resulted spectra, it was clear that treatment materials have been added to paper but there was not any sign of paper degradation. Accelerated aging caused to production of carbonyl adsorption of the spectra in 1742 $\mathrm{cm}^{-1}$. It was indicated decay of cellulose and presence of new degradation products which results to aesthetical change of paper. Aged samples compared with unaged ones did not show structural deformation in paper due to treatment materials and there was not any sign of breakdown in cellulose linkages. The both of $100 \mathrm{ppm}$ and $200 \mathrm{ppm}$ treated samples were without damage after accelerated aging. In general, the both treatments do not affect paper structure according to results of infrared spectra.
\end{abstract}

Keywords: Fungicide, Thiophanate-methyl, Carbendazim, Paper, FTIR, Conservation, Restoration.

*Corresponding author: mahboob9067@yahoo.com 


\section{يزوهن}

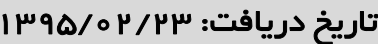

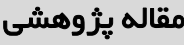

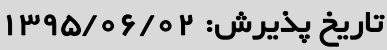

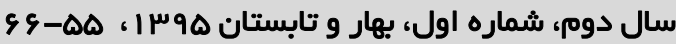

\section{ارزيابى تأثير قارج كثىهاى تيوفانات متيل و كاربندازيم بر ساختار كاغذ با استفاده از طيفسنجى مادونقرمز تبديل فوريه}

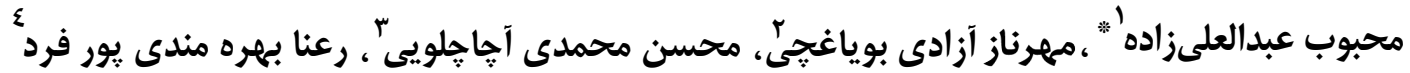

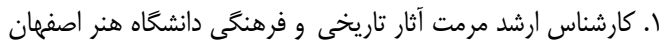

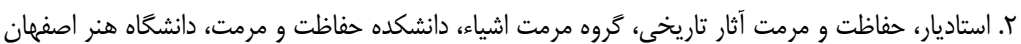

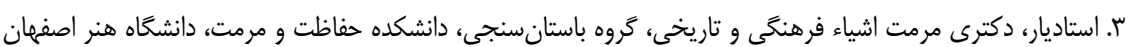

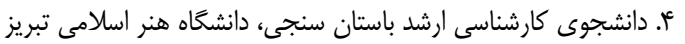

جكيده

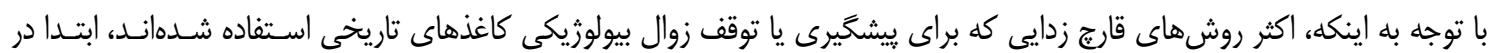

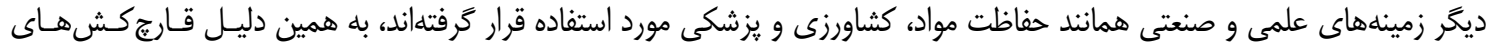

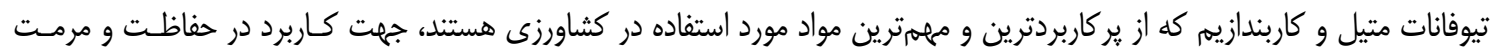

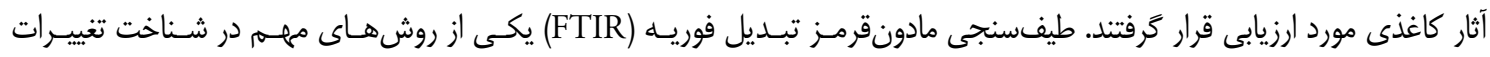

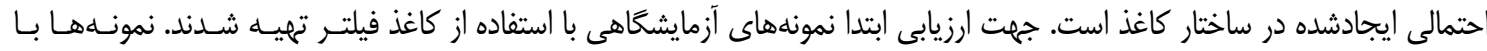

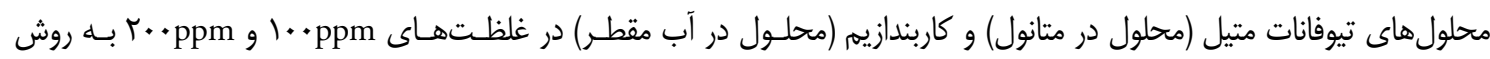

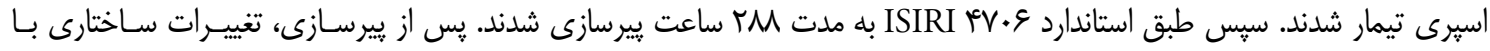

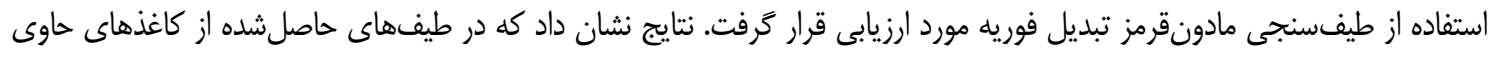

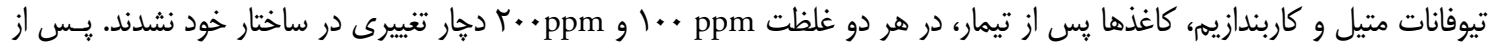

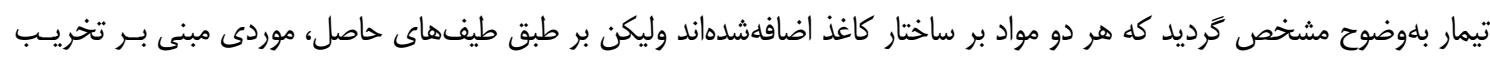

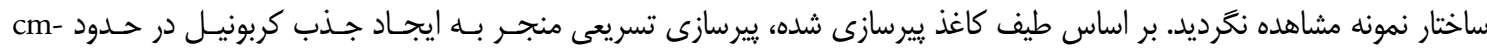

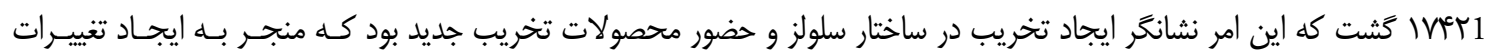

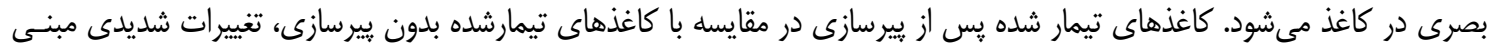

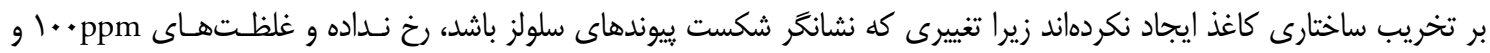

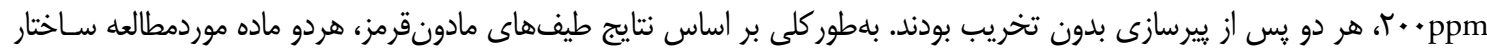
كاغذ را تحت تأثير قرار نمى دهد. كلمات كليدى: قارجكش، تيوفانات متيل، كاربندازيه، كاغذ، FTIR، حفاظت، مرمت.

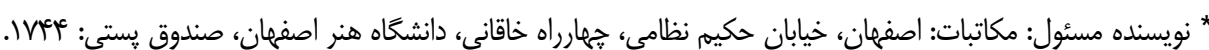

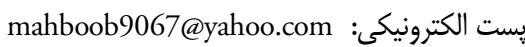

Cب حق نشر متعلق به نويسنده(كان) است و نويسنده تحت مجوز Creative Commons Attribution License به مجله اجازه مى دهد مقاله جاب شده را با ديخران به اشتراك بحذارد منوط بر اينكه حقوق مؤلف اثر حفظ و به انتشار اوليه مقاله در اين مجله اشاره شود. 


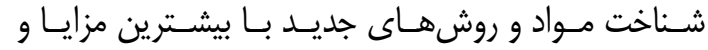

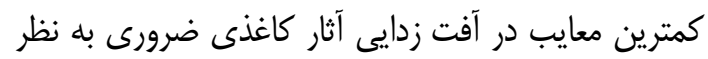

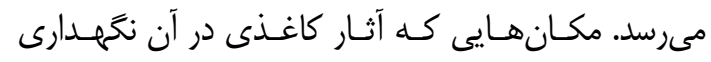

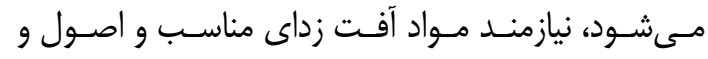
روشهاى استاندارد و كم تخريـب هسـتند. امــروزه تعـداد

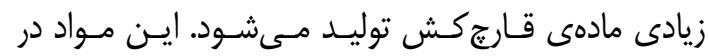

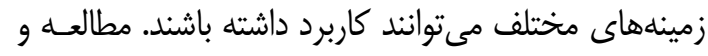

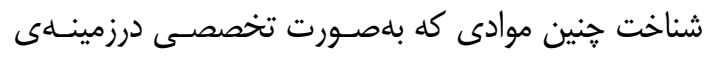

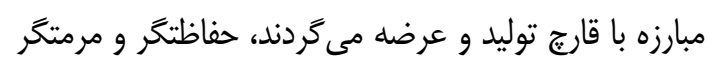

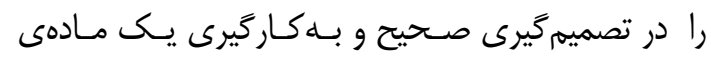
مناسب در امر قارجزدايى آثار كاغذى يارى مىرساند. موادى مثل اكسيد اتيلن و تيمول كه تـاكنون در امـر مارك

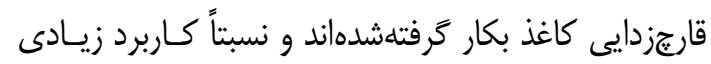

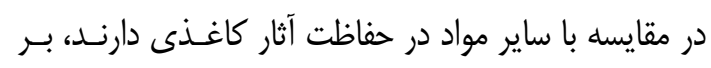

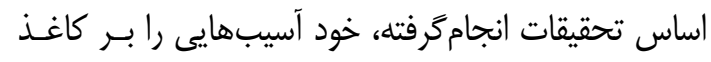

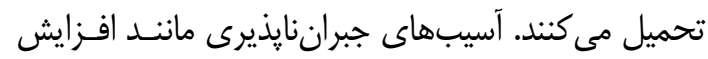

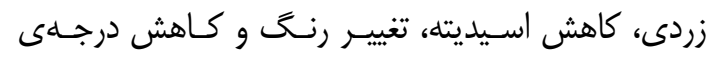

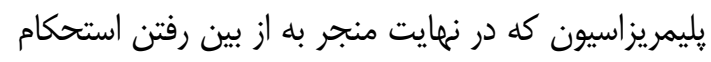

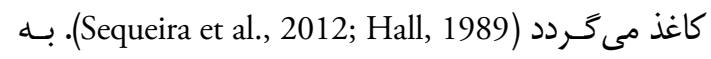
همين خاطر، هماروزه شاهد انجام مطالعات كستردهاى درد

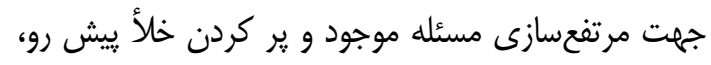

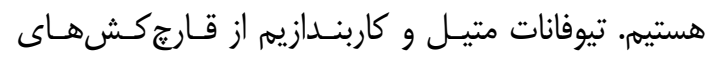

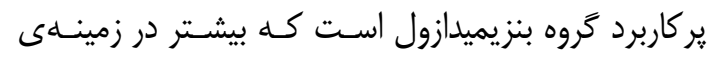
كشاورزى جهت مبارزه با طيف وسيعى از قارجها بـهـ كـار

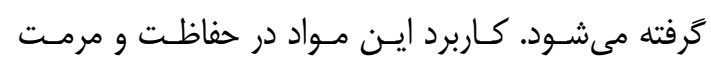

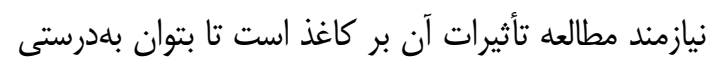

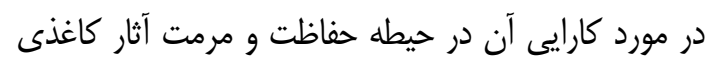

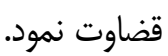

هدف از كاربرد مواد قارج كش كمك به حفاظت اثر و

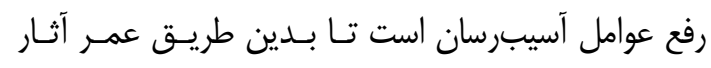

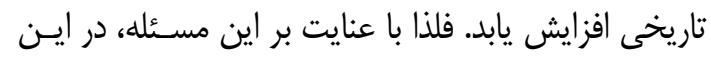

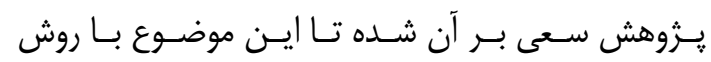

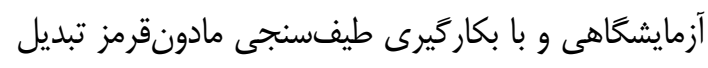

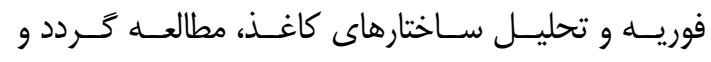

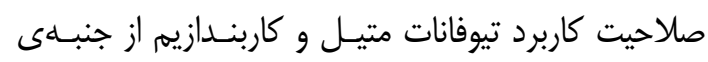

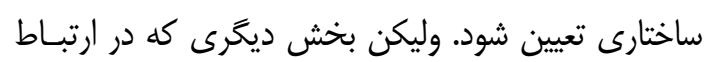

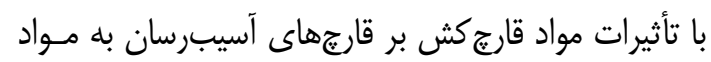

بزيهاستانسنجيج

- (1) - مقدمه

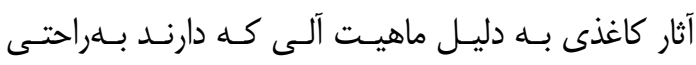

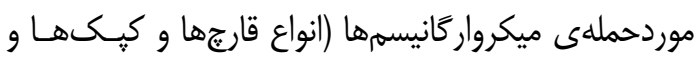
باكترىها) قرار مى گيرند و بهعنوان مواد غـذايى از آنهـا تغذيه مى كنند. در صورت ايجاد محيط مناسب، اين عوامل

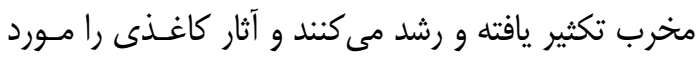

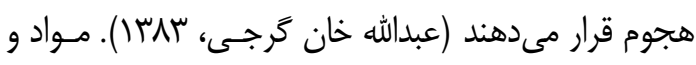

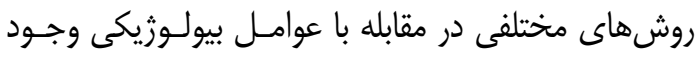

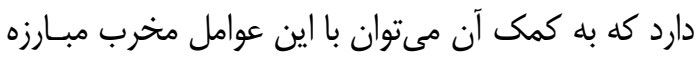
كرد. يكى از اين روشها كه بسيار متداول است؛ اسـتفاده

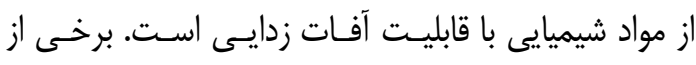

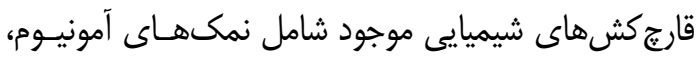

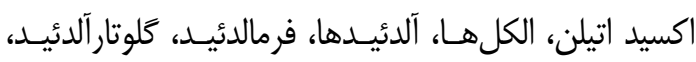

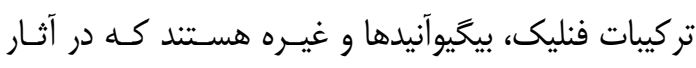

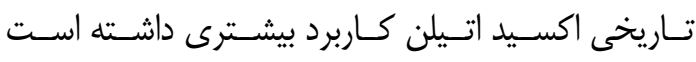
(Gutarowska, 2012)

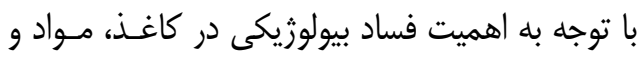

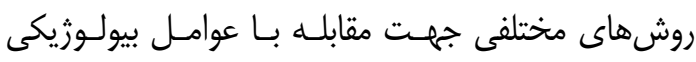

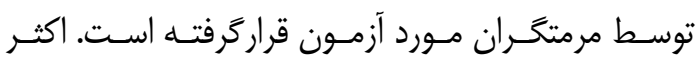

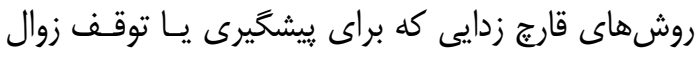

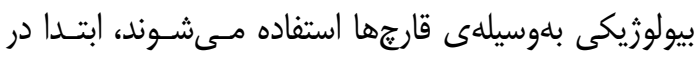

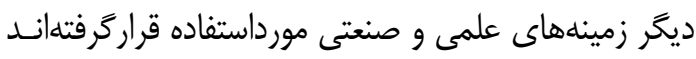

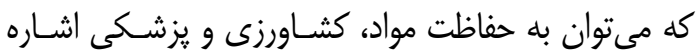

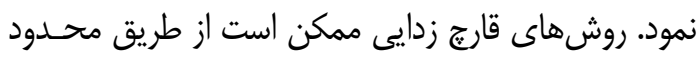

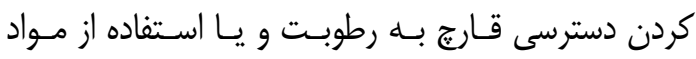

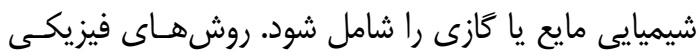

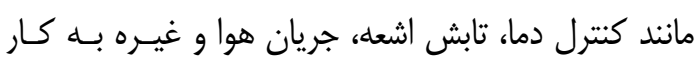

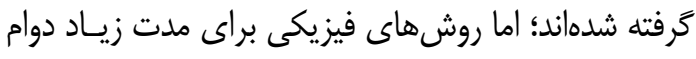

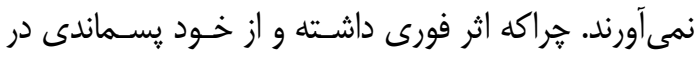

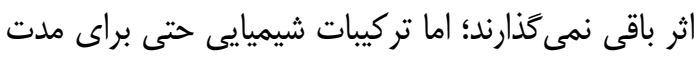

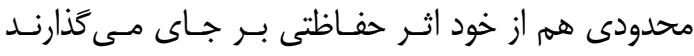
(Sequeira et al., 2012)

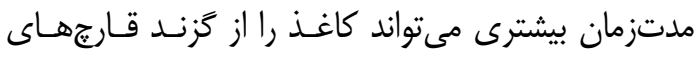

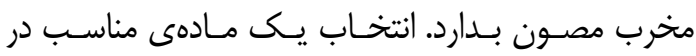

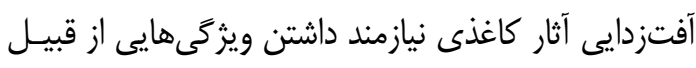

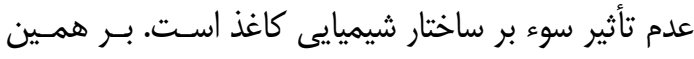

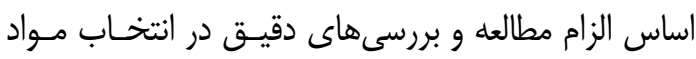
وجود دارد.

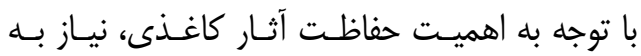


تركيـب آب و الكـل، اثـربخشتــر از الكـل خـالى اســــ

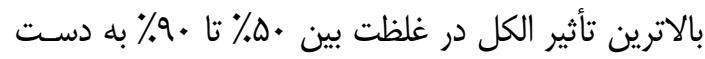
مى آيد و به نوع الكل نيز بستخى دارد (Bacilkova, 2006).

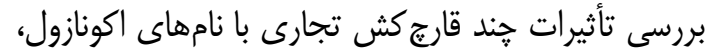

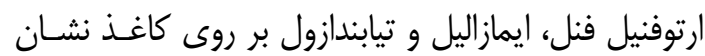

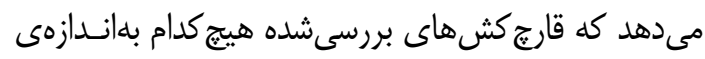

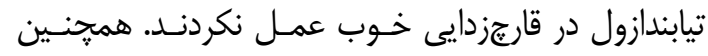

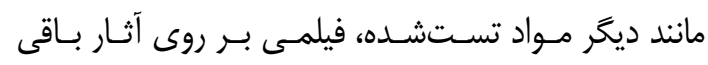
نخذاشت. در مورد اثرات تيابندازول روى كاغذ، كمى تغييـر

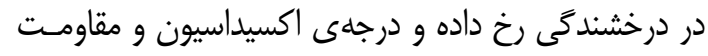

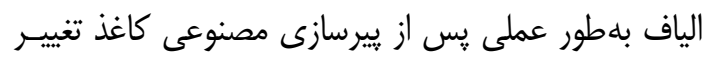

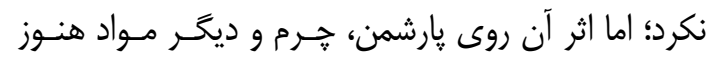

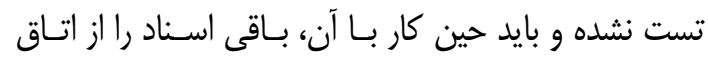

خارج كرد (Rakotonirainy et al., 1999).

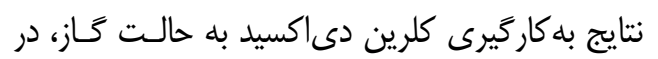
كنترل حملات قاريى آثار كاغذى، نشـانكَ رِايين بـودن

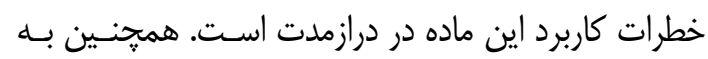

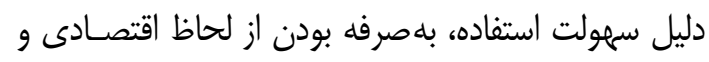

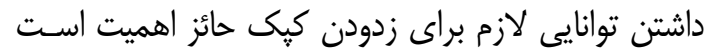

.(Weaver-Meyers et al., 1998)

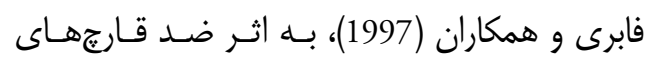
مختلف در كنترل زوال بيولوزيكى ناشى از قـارج يرداختـهـ

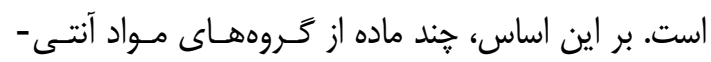

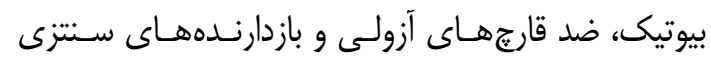

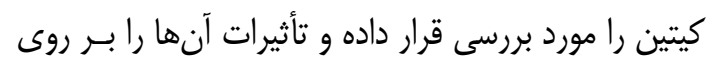

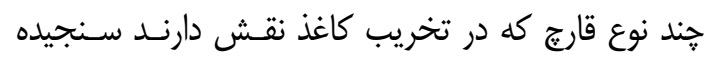

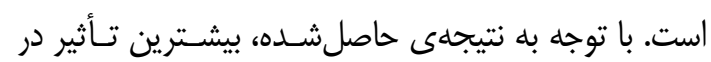

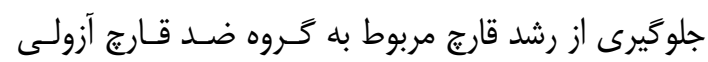

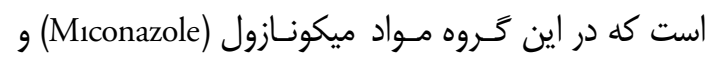

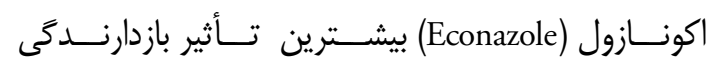

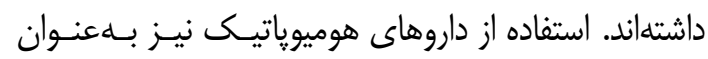

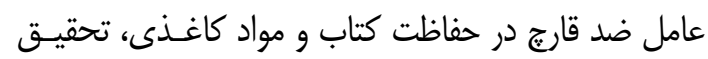

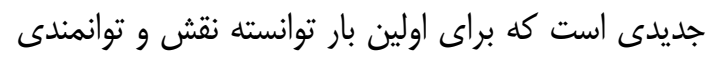

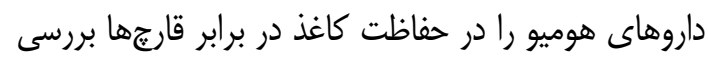

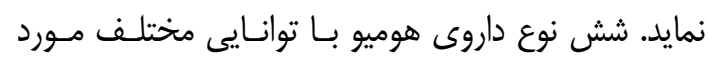

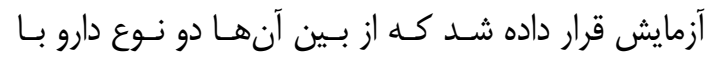

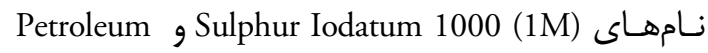

كاغذى است، بر اساس نتايج بهدستآمده در اين يزوهش و استناد به اين نتايج در مجالى ديخر انجام مى گيرد.

\section{r- ييشينهى تحقيق}

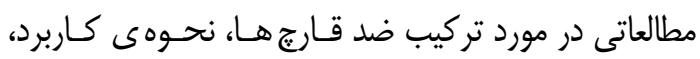

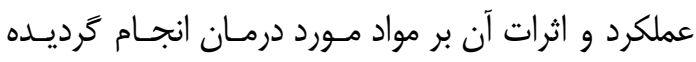
است (Sequeira et al., 2012). رومن و همكـاران (2013)

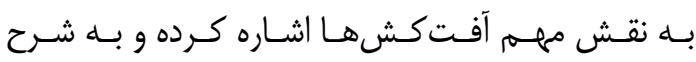

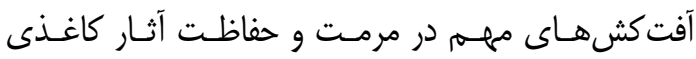

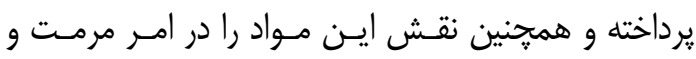

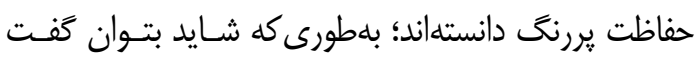

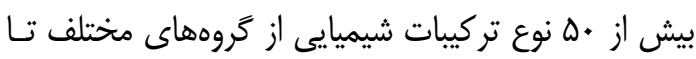

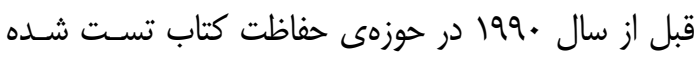

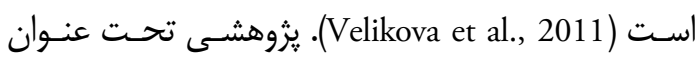

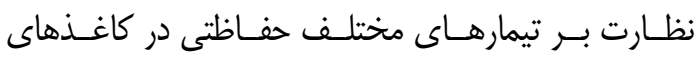

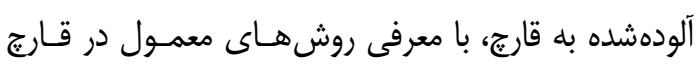

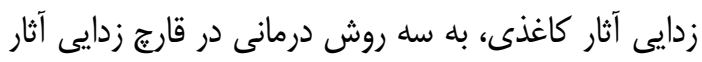

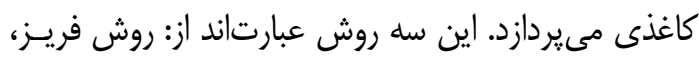

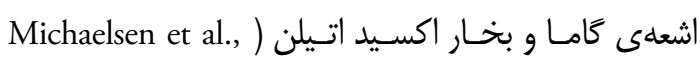

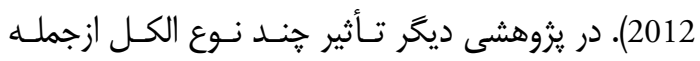

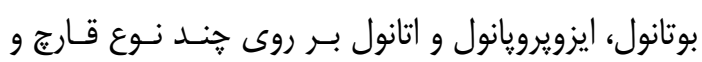

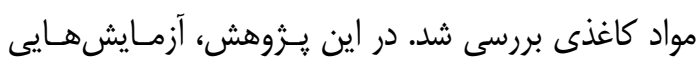
جهت دست يافتن به اطلاعاتى دربارهى تأثيرات بخـارات أنسات

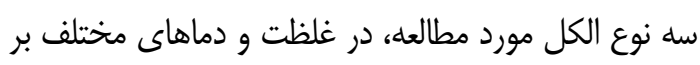

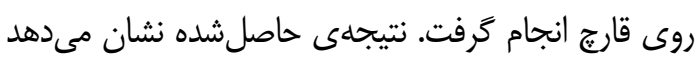

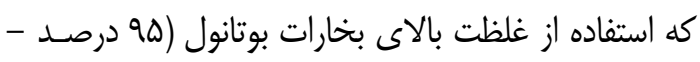

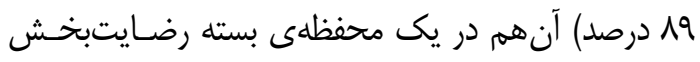

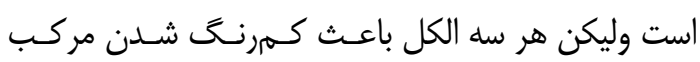
شدند (Bacilkova, 2006). در مقالهاى با عنوان بررسى اثر لثر

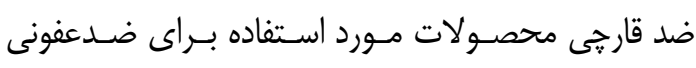

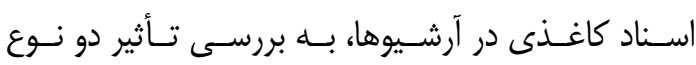

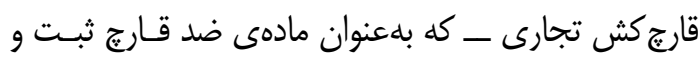

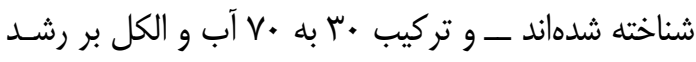

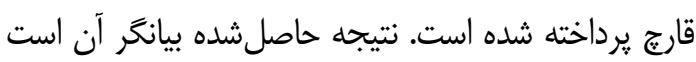

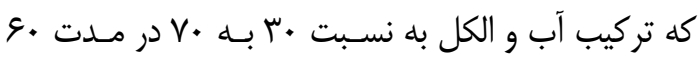

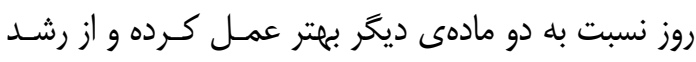
قارجها جلوكيرى نموده است (Adelantado et al., 2005). 
شدند (Lamberth and Dinges, 2012, p. 115). قارجكش تيوفانات متيل از سال •عال19 در قارج زدايى

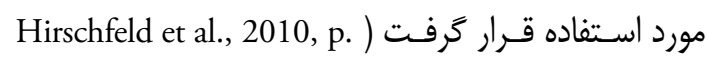

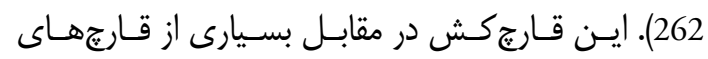

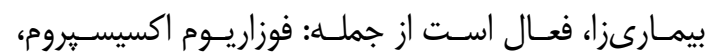

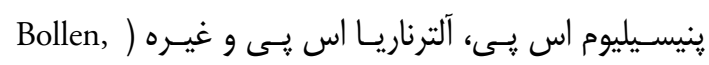

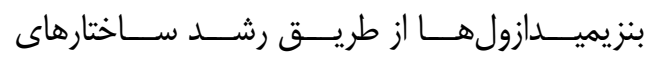

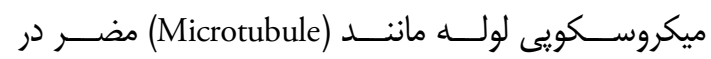
سلولهاى قارجى عمل مى كنند. درنتيجه از تقسيم سلولى مالى

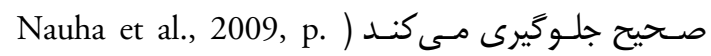

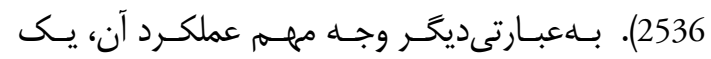

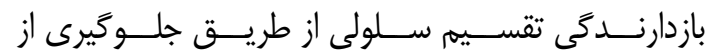

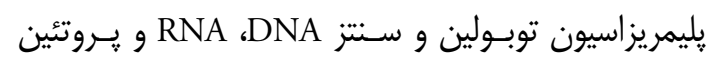

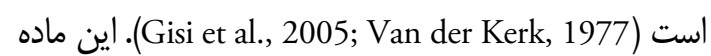

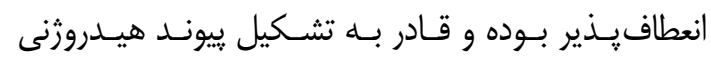

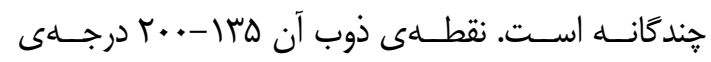

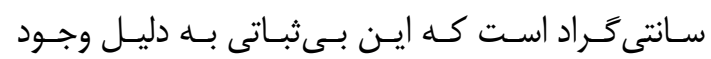

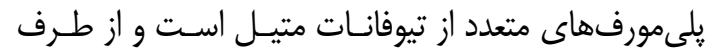

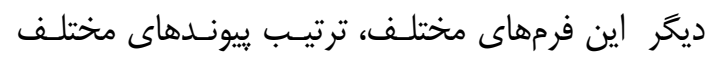

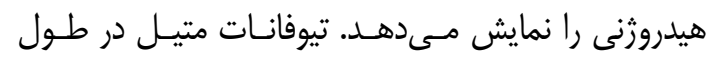

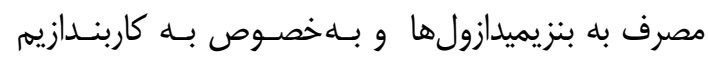

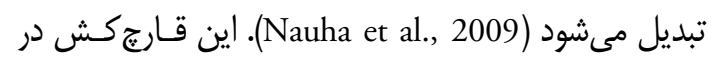
محيطهاى اسيدى يايدار است و بله نور حساس بـوده و در محيطهاى قليايى نيز يايدارى كمترى دارد. در دماى زيسر

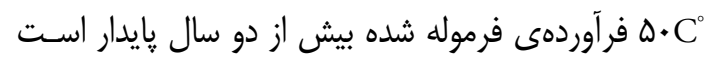

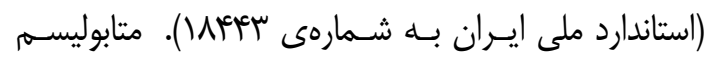

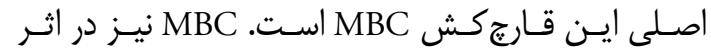

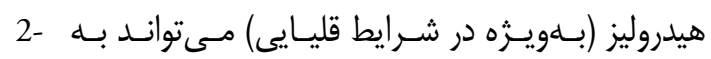
و pH=q aminobenzimidazole

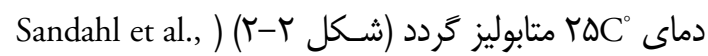
(2000, p. 125

رونسـ تخريسب و تبــيل تيوفانـات متيـل بـــ MBC

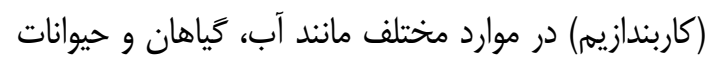
مشترك است. MBC يا كاربندازيم همـان طـور كـه قـبلاً كفته شد، با نـام [methyl benzimidazol-2-ylcarbamate]

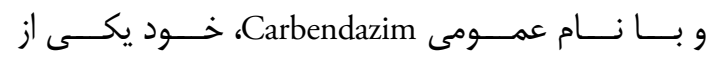

30 تأثير بيشترى را نشان دادند. اين داروها بىخطر بوده و

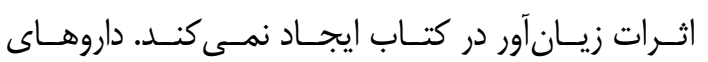

هوميوياتيك براى انسان سمى نيستند (Garg, 1995). قارجكش تيوفانات متيـل (Thiophanate Methyl) از

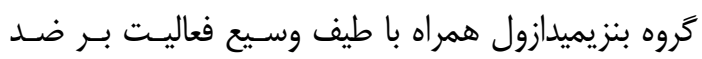

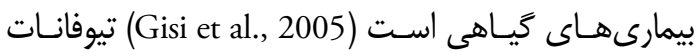
متيل بلصصورت بلورهاى بىرنغ است (استاندارد ملى ايران

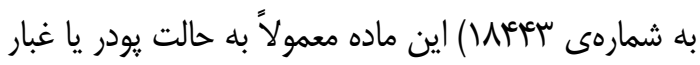

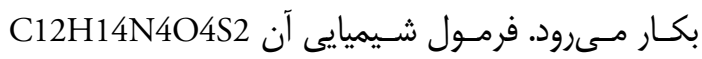

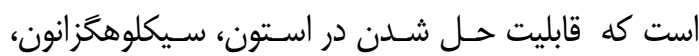

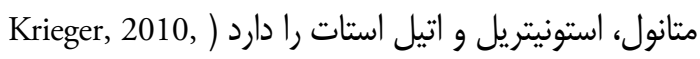

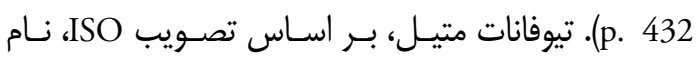

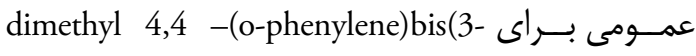
toxicological evaluations, ) اســ thioallphanate) .sponsored jointly by FAO and WHO, 2006, p. 557 كاربندازيم (متيل-r - بنزيميدازول كاربامات) نيز يك

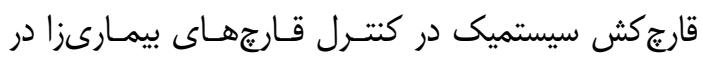
طيف وسيع است. بلهورى كه كاربندازيم بلهعنوان مـادهى

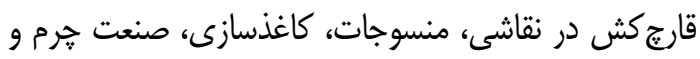

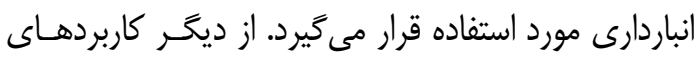
اين ماده، مىتوان به حفاظت از ميـوه و كشـاورزى اشـاره نمود (Farag et al., 2011). حلقهى بنزيميدازول (Benzimidazole) مايهى اصـلى

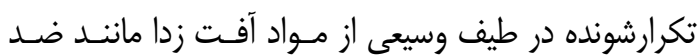

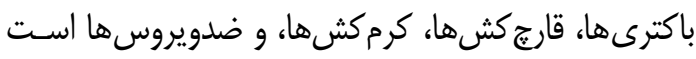
و درزمينهى كشاورزى و داروسازى كاربرد بسيار دارد. يــنج

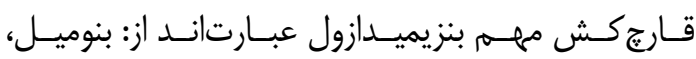

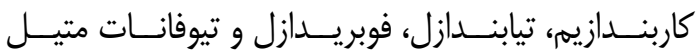

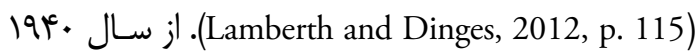

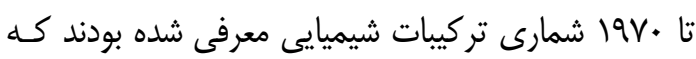

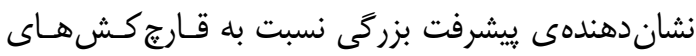

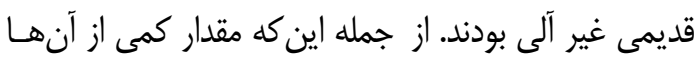

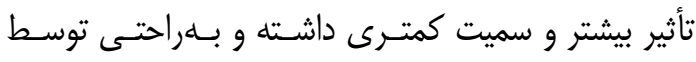

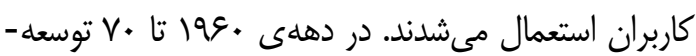
ى تحقيقات سرعت يافت و قارجكش هاى متعددى روان روانه سى بازار شد. در اين دهل، اولين طيف وسيع قارج كشهـاى سيستميك (Systemic) شامل تيابنـدازل در بـازارهـا ارائهـ 


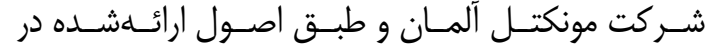

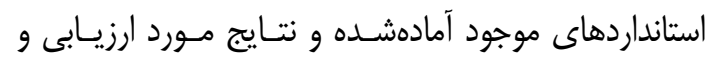
تحليل قرار داده شد. قارج كش تيوفانات متيل و كاربندازيم از شركت ملى تلى

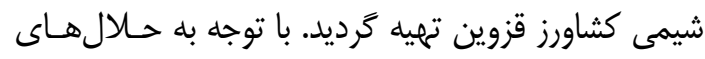

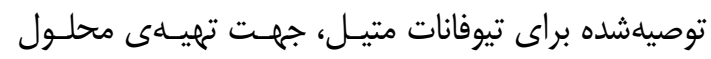

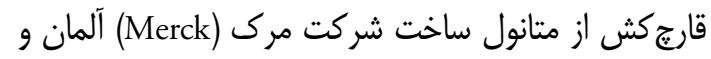

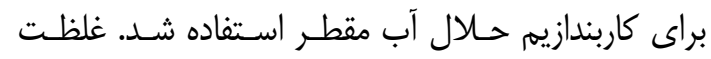

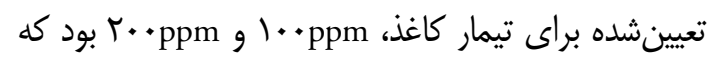
بر روى كاغذها اسبرى گرديد. هدف از تعيين اين غلظت- تبار

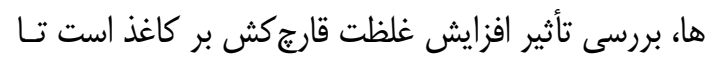

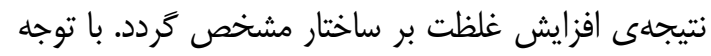

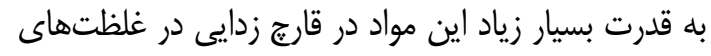

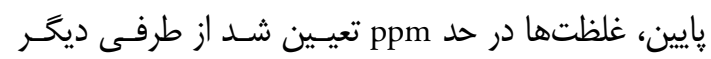

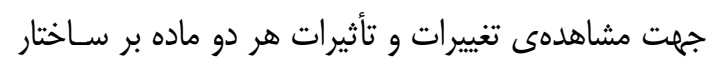

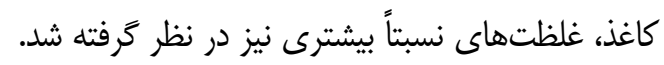
كاغذهاى تهيهشده، طبق استاندارد ISIRI (استاندارد

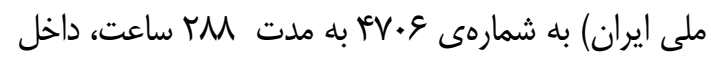

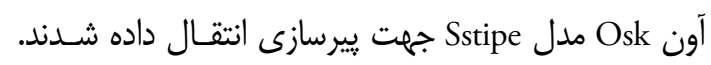

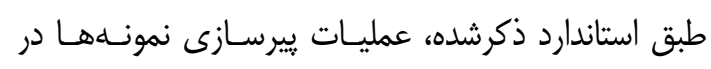

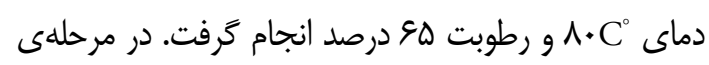

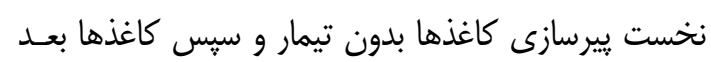

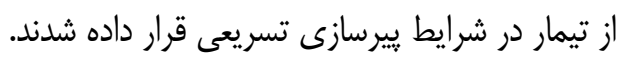

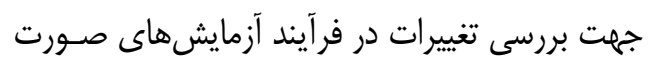

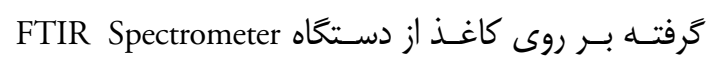

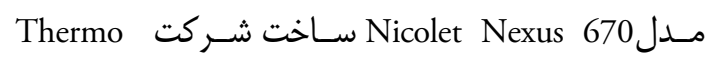
مicolet

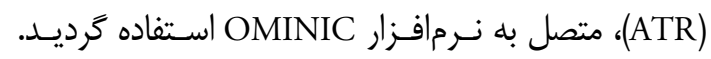

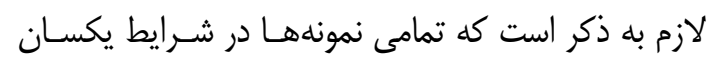

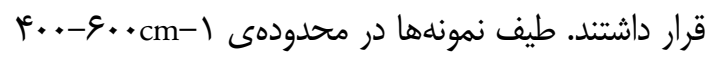

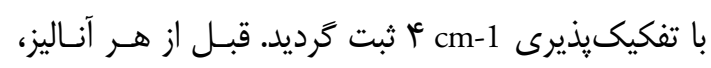
دستخاه با طيف هوا بلعنوان زمينه، كاليبره مىشد.

\section{F}

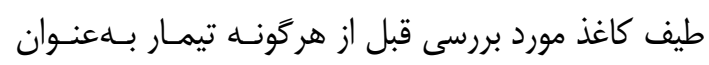

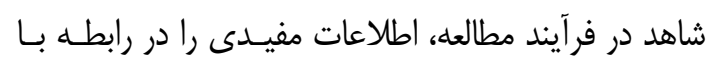

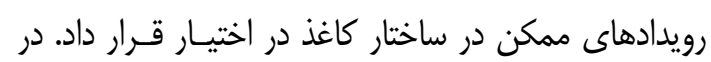

قارجكشهاى سيستميك از گروه بنزيميـدازول بـا كـاربرد وسـيع اسـت (cycon et al., 2011, 574). خاصـيت قارج كشى تيوفانات متيل ممكن است درنتيجـهـى تبـديل

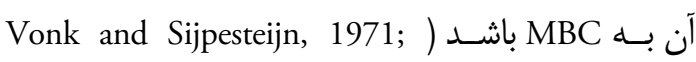
مثائ، خاصبيت قارجثي 1977 مشابه، خاصيت قارج كشى تيوفانات ممكن است به سـبب لبـ

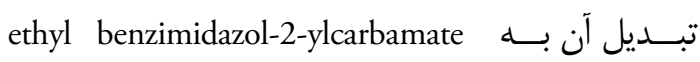
(Vonk and Sijpesteijn, 1971, 160) باشد اند بـ (EBC)

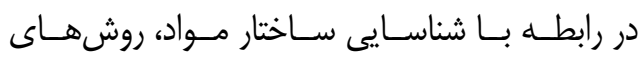

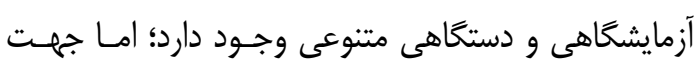

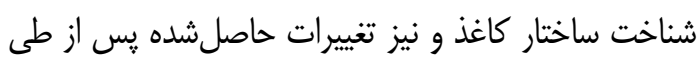

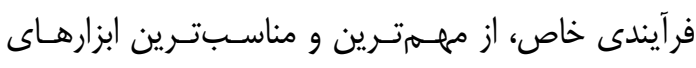

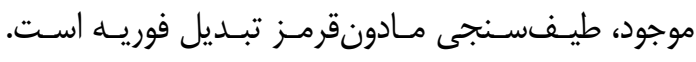

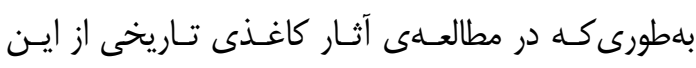

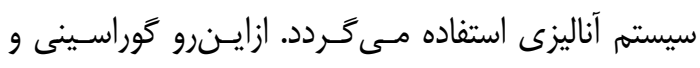

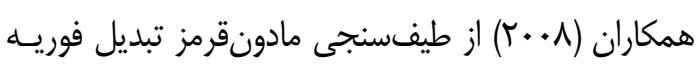

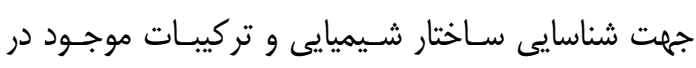

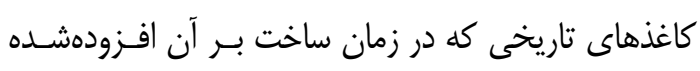

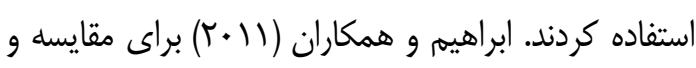

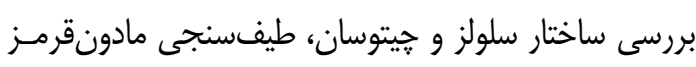

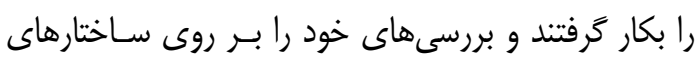

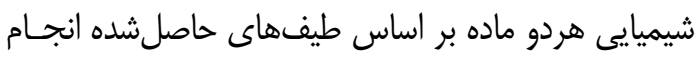

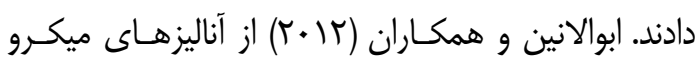
رامان و طيفسنجى مادونقرمز در شناسايى ساختار اسناد

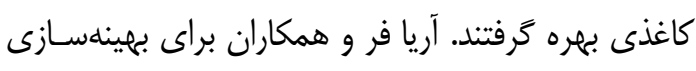

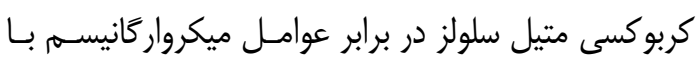

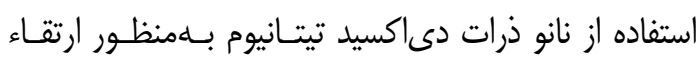

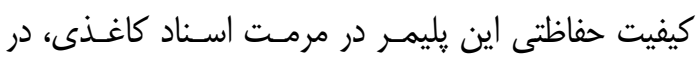

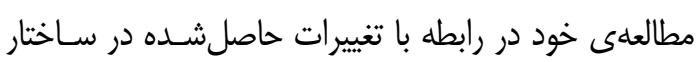
كاغذ از طيفسنجى مادونقرمز استفاده كردنـــ (آريـافر و

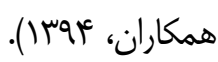

\section{ب- مواد و روشها}

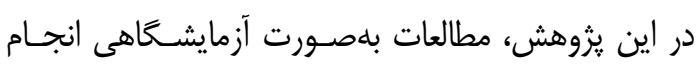

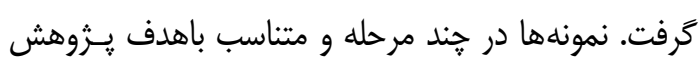

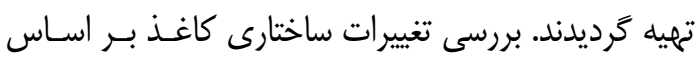
نمونههاى كاغذى با استفاده از كاغذ فيلتر M\&N تئل 
تحت تيمار قرار كرفته است، اضافه شدن برخى از ييكهــا

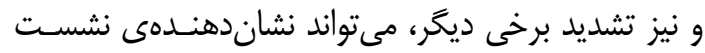

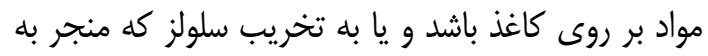

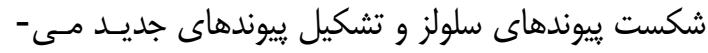

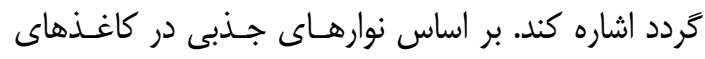

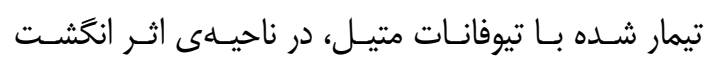
تغييرات شديدى در ساختار كاغذ مشاهده نمى شــود. عـدم

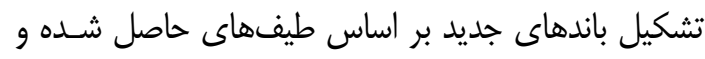

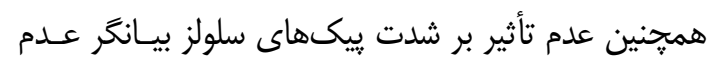
تخريب سلولز تحت تيمار با تيوفانات متيل اسـت. هراكـه

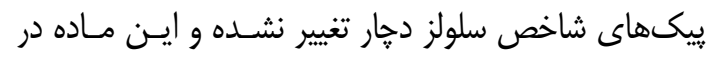
هر دو غلظت مورد بررسى نتيجهى يكسان دارد؛ بنـابراين

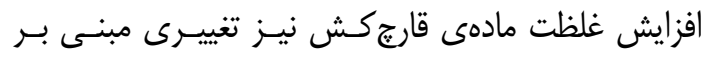

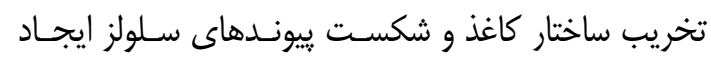

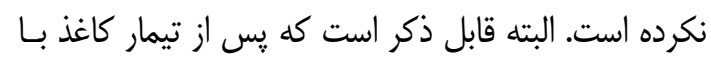

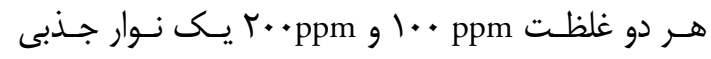

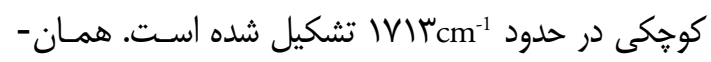

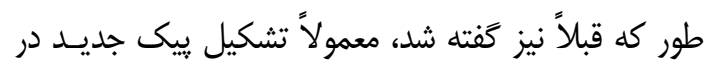

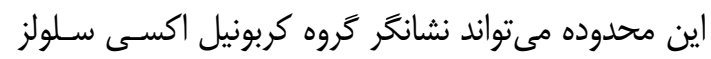

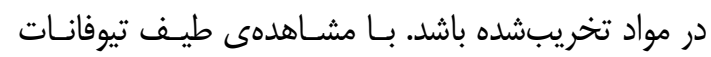

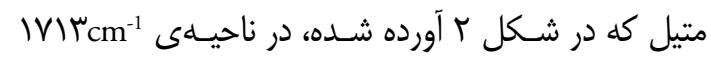

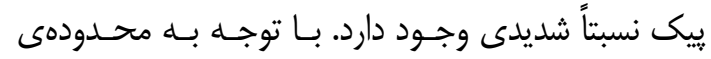

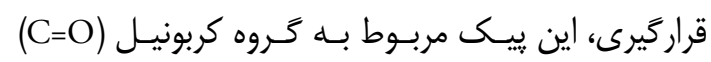

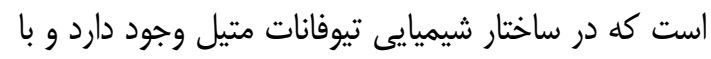

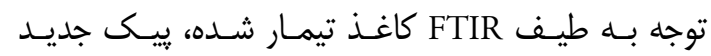

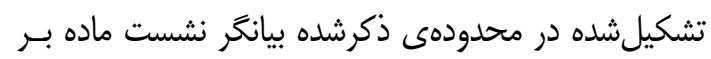

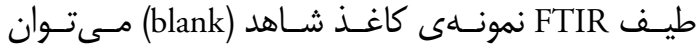
ييكهاى شاخص سلولز را در ناحيسهى

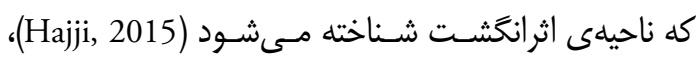

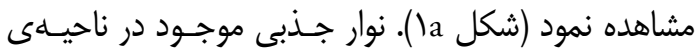

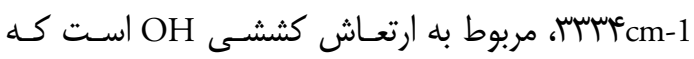

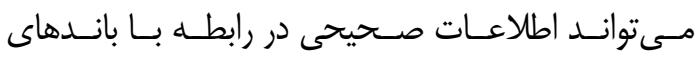

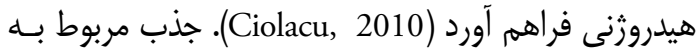
ارتعاش كششى كروه CH سلولز، در ناحيهى cm-1

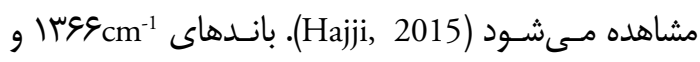

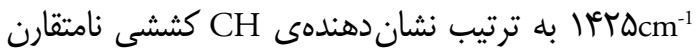

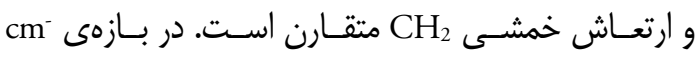

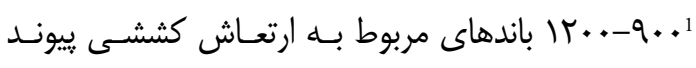

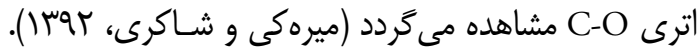

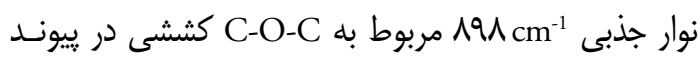
glycosidic ساختار آمورف سلولز شناخته مسىشـود (Ciolacu, 2010).

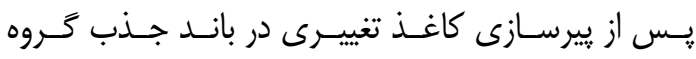

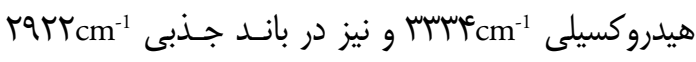

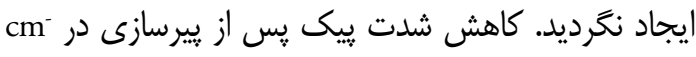

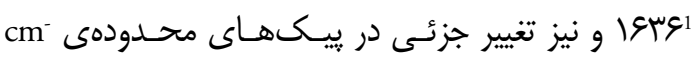

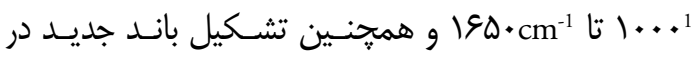

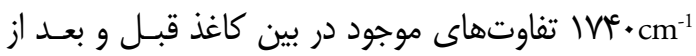

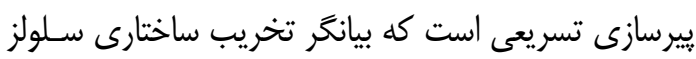

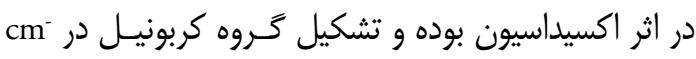

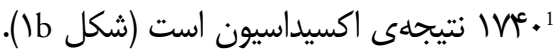

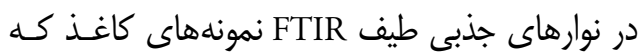

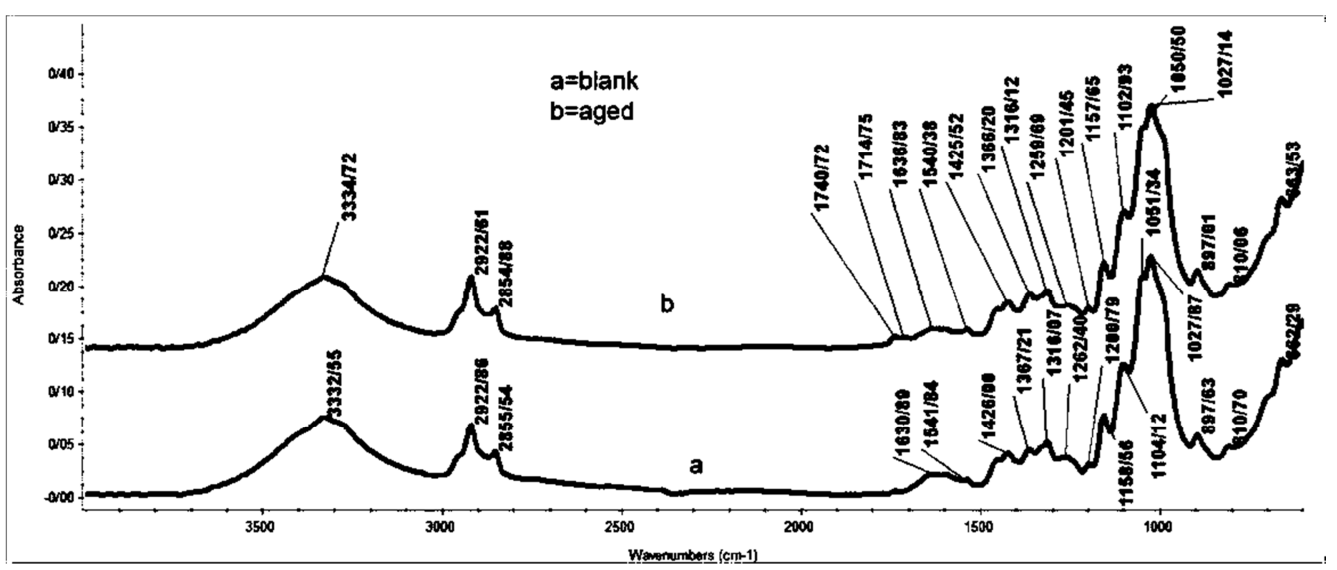

شكل (: طيف ATR-FTIR كاغذ شاهد و كاغذ بيرسازىشده 


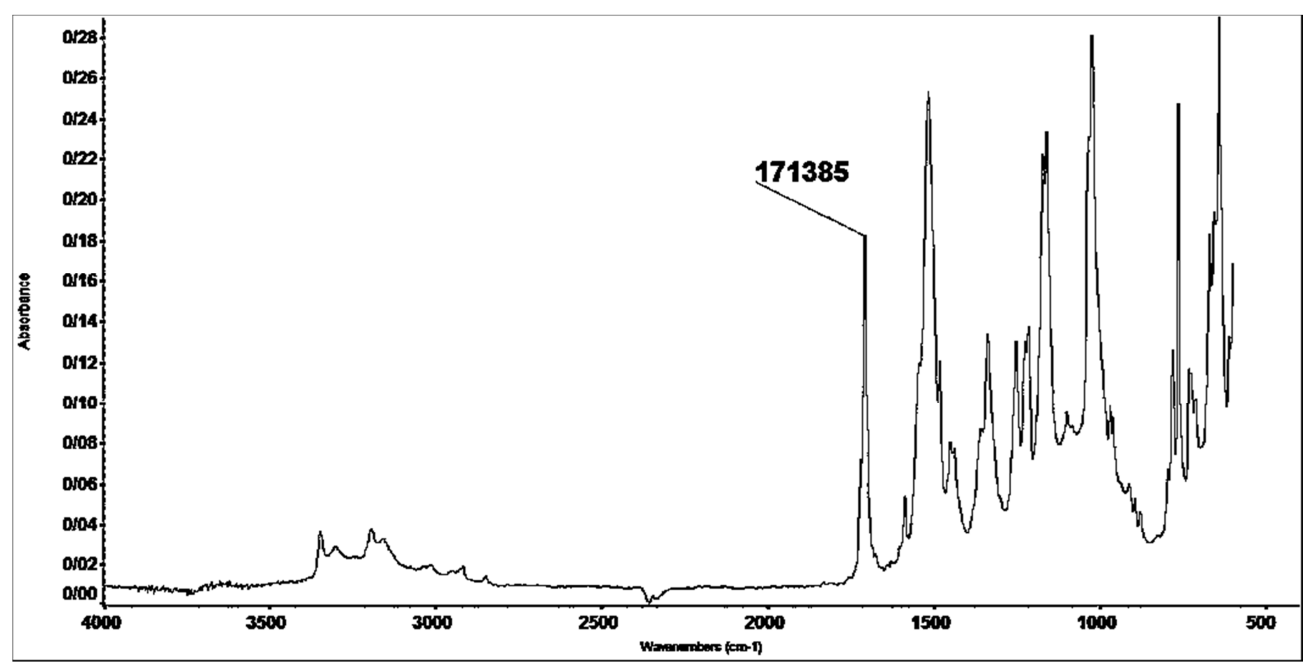

شكل r: طيف FTIR فرمولاسيون تجارى تيوفانات متيل (تويسين ام \% V)

كششى و VY

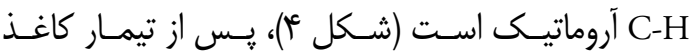

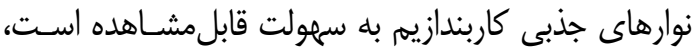
در حدود كاغذ حاوى تيوفانات متيل نيز ديده شد و در اين نمونه نيز ييك كربونيل موجود در ساختار كاربندازيم يـس از تيمـار،

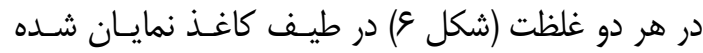

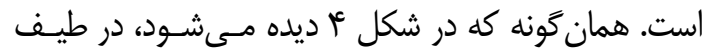

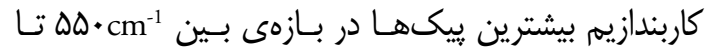

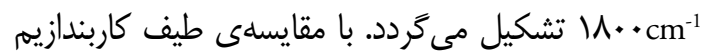
با كاغذهاى تيمار شده با همين ماده، تغييـرات و تـأثيرات

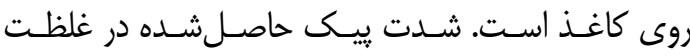

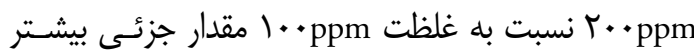
بوده و بر اين اساس با افزايش غلظت ماده بر شدت ييـك كربونيل نيز افزوده شده است.

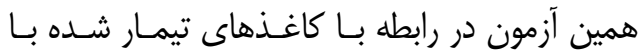
كاربندازيم با توجه به باندهاى مهـم كاربنـدازيم در طيـف

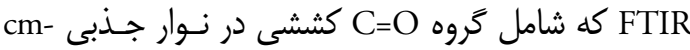

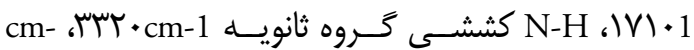

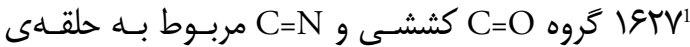

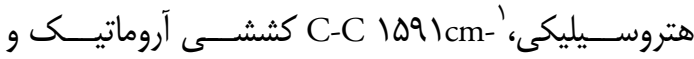
C-O

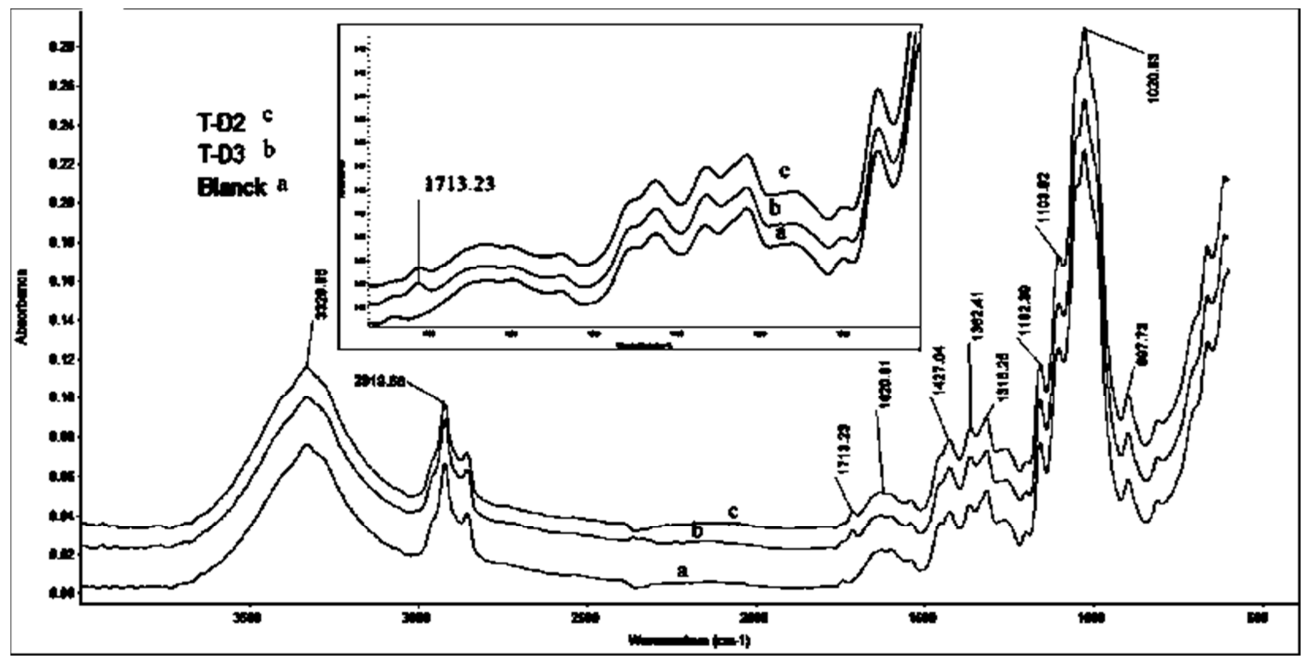

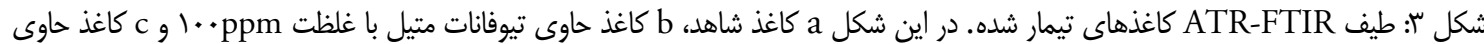

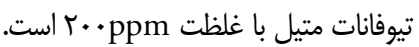




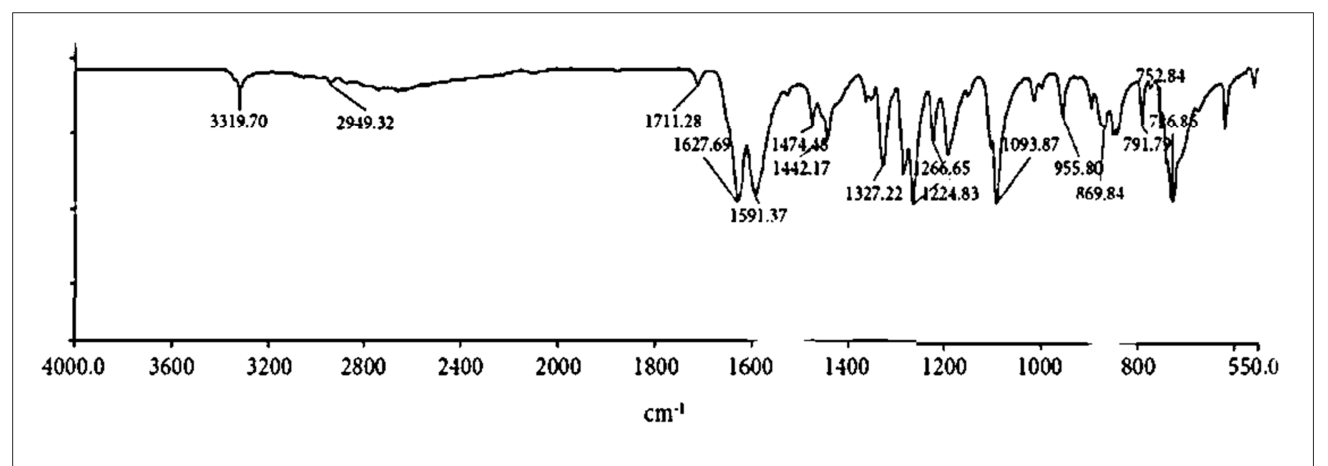

شكل عأ: طيف مربوط به قارجكش كاربندازيم (Sanches et al., 2013)

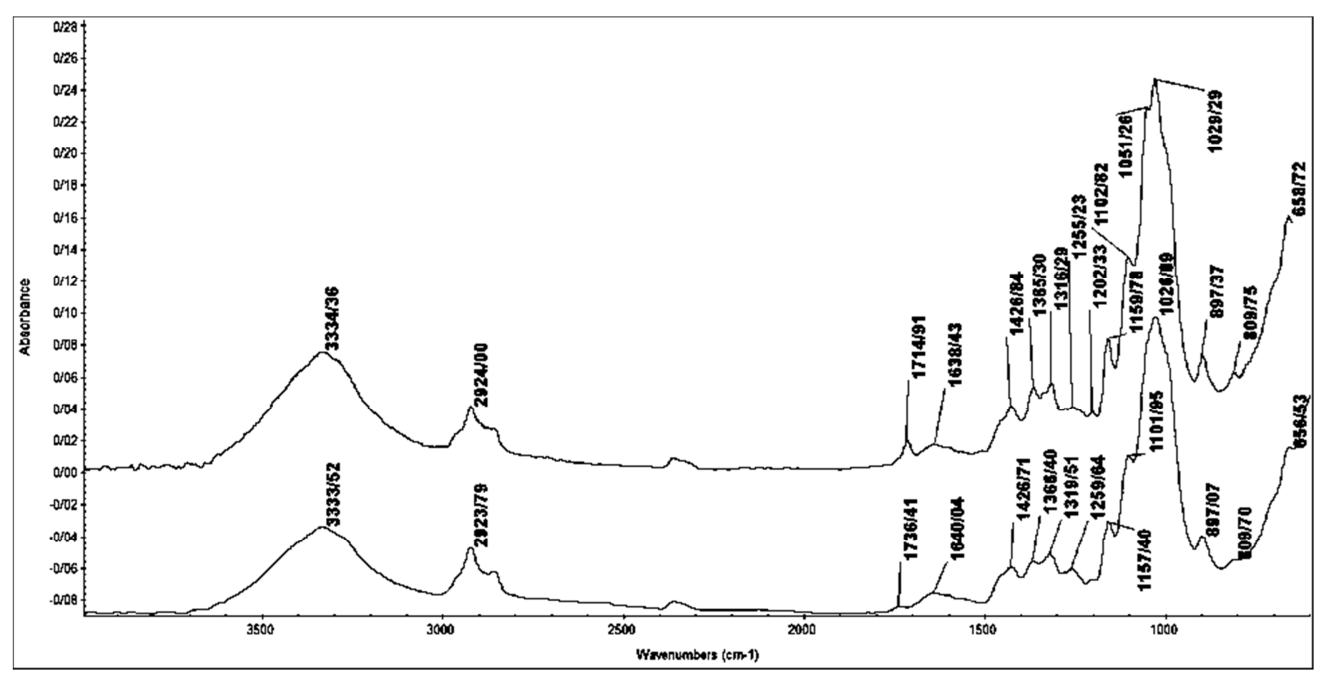

شكل ه: باندهاى جذبشده در طيف ATR-FTIR كاغذ تيمارشده با غلظت Ppm ب.p از مادهى كاربندازيم و كاغذ بدون تيمار

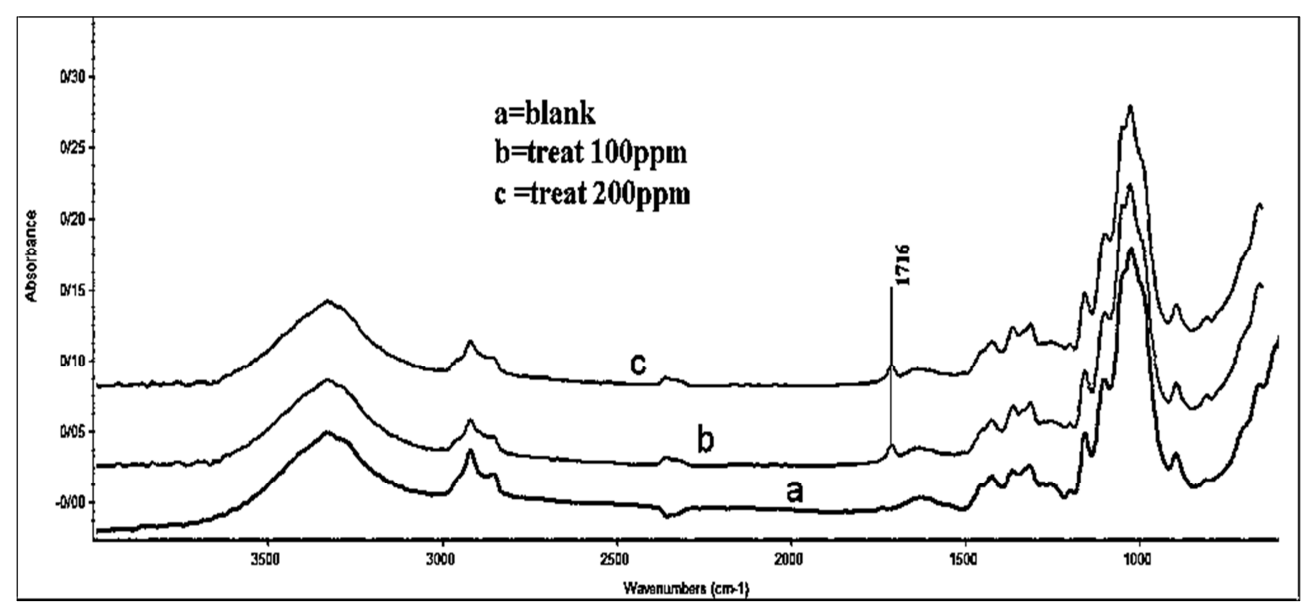

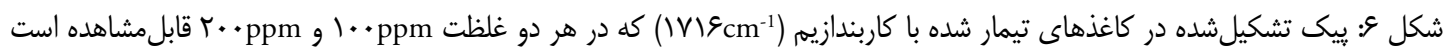




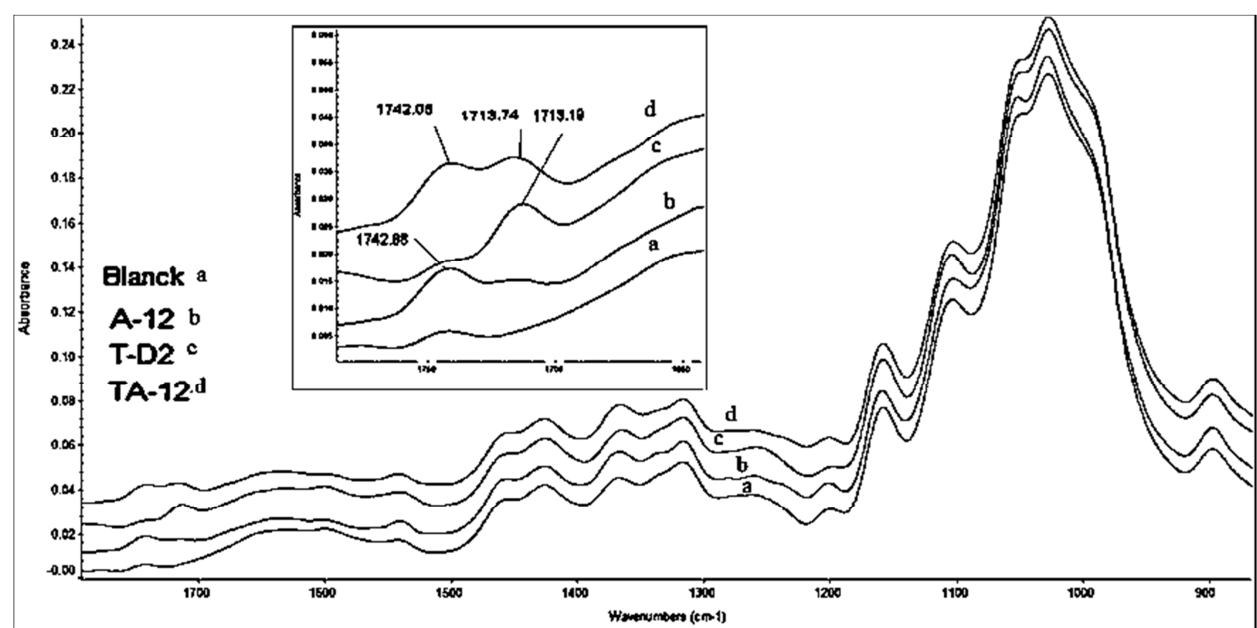

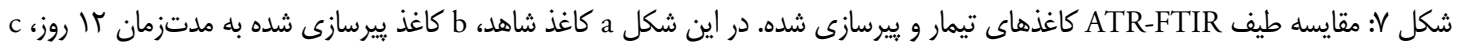

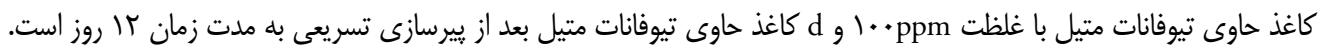

نداده است.

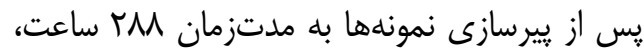

در طيف مربوط به كاغذ كه در شكل V مشاهده مى لرود،

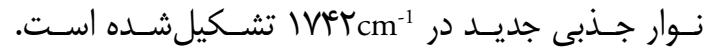
همان طور كه كَفته شد، تيمار كاغـذ بــا تيوفانـات متيـل

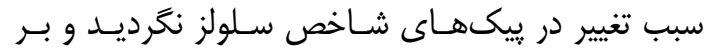

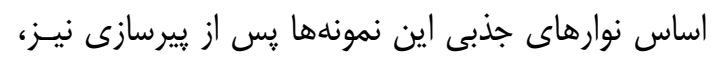

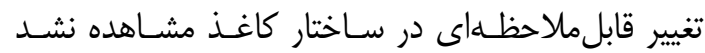
(شكل V). البته تنها تغيير ايجادشده در اين نمونسهــا در IVFrcm

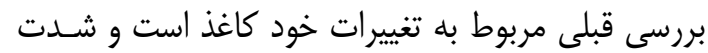

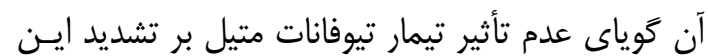

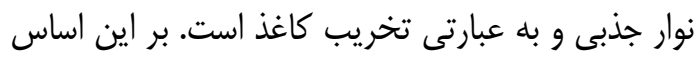

كاربندازيم بر طيف سلولز مشهود اسـت. جـذبـهـاى cm 1 آمورف در ساختار سلولز بسيار حساس بوده و يهـن شـدن

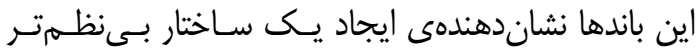
هستند؛ بنابراين در مقايسهى طيفهاى قبل و وانسان بعد از تيمار كاغذ با كاربندازيم (شكل ه) در هر سه جذب مطـرحشــــ

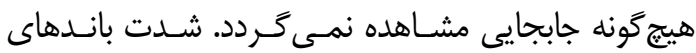

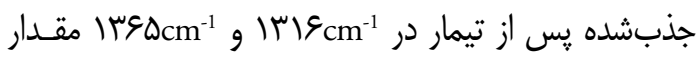

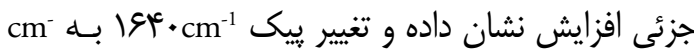

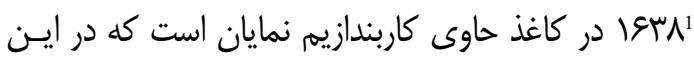
محدوده گروه C=O كششى و C=N مربـوط بـاعه حلقـهى هتروسـيليكى كاربنـدازيم قـرار دارد. بــر طبـق بانــدهاى

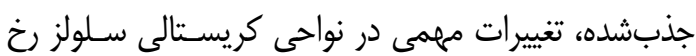

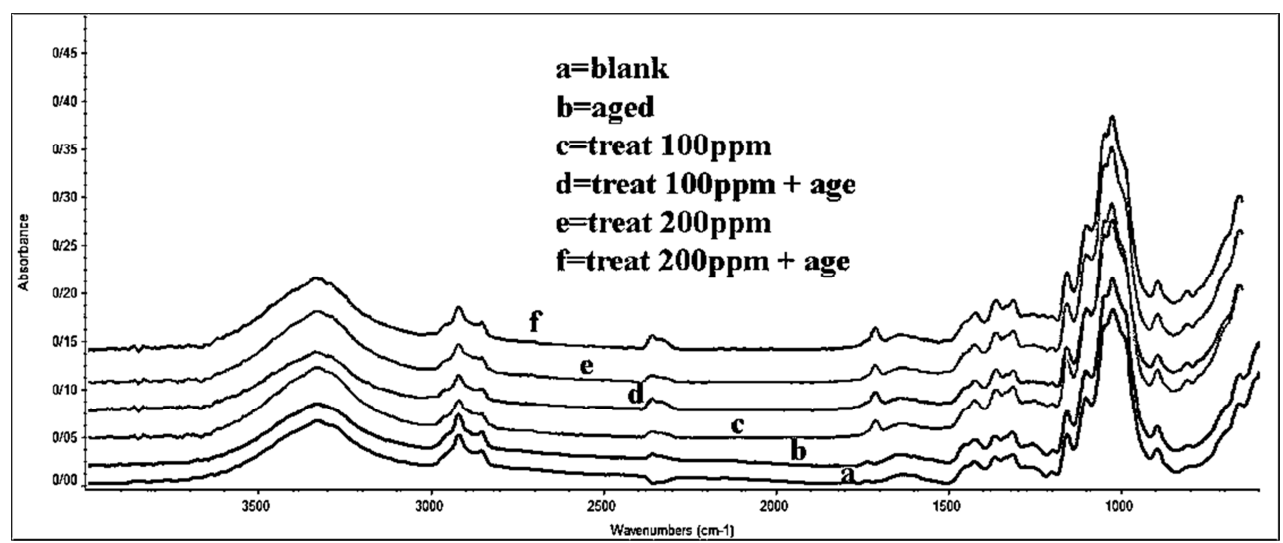

شكل م: طيفهاى كاغذ شاهد و تيمار قبل و بعد از ييرسازى 


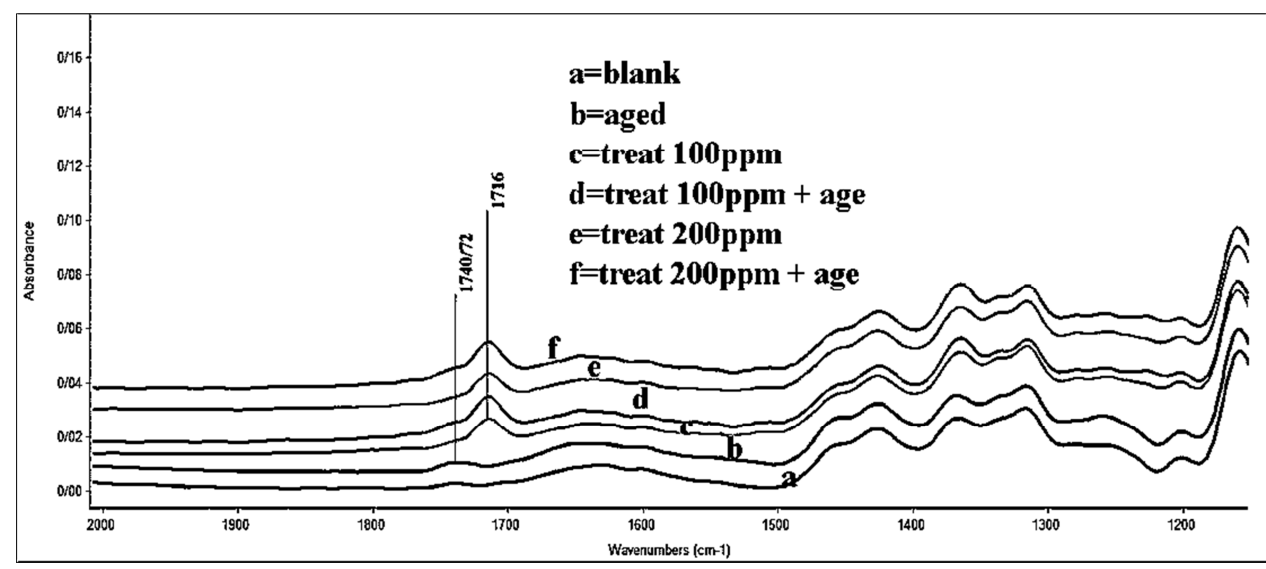

شكل 9: ييك كربونيل در كاغذهاى تيمار شده، قبل و بعد از يبرسازى

بررسى دقيق است كه در مطالعهاى ديخر مىتوان به اين

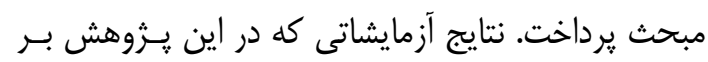

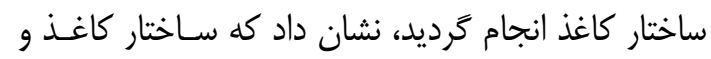

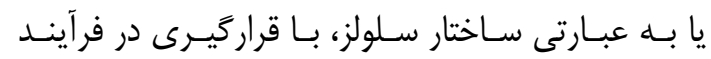

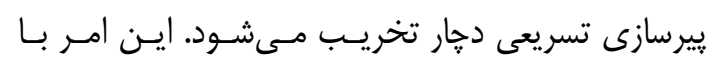
تشكيل ييى كربونيل در طيف كاغذ يِيرسازى شده اثبات

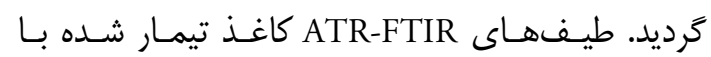

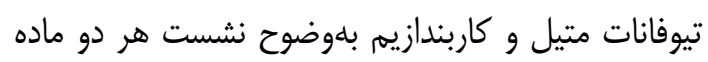

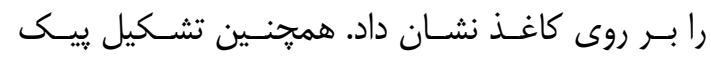

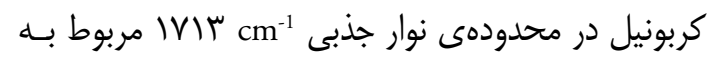

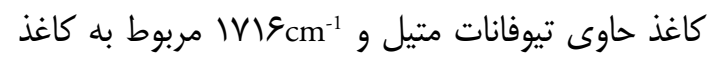

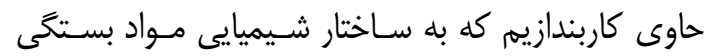

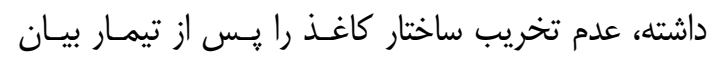

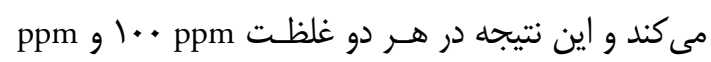

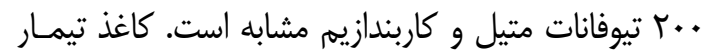

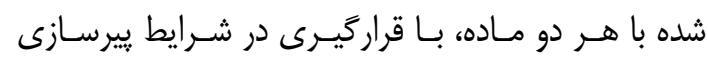

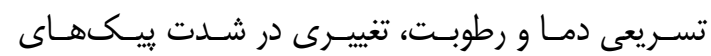
حاصلشده در برنداشته و عدمتغيير شدت يبيـى كربونيـل تئل

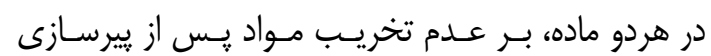

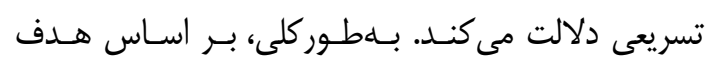

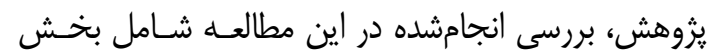

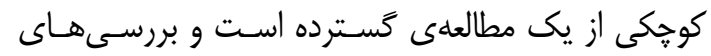

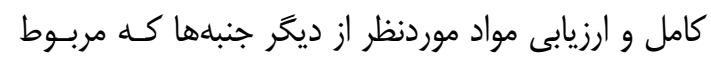

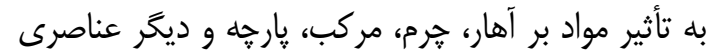

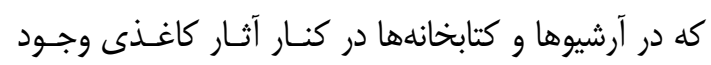

اين نتايج گوياى عدم تأثير تيوفانات متيل بلهعنـوان مـاده

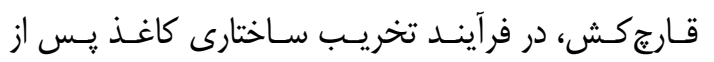
ييرسازى تسريعى است. شكلهاى ^ و 9 نيز مربوط به نتايج تيمار كاربندازيم

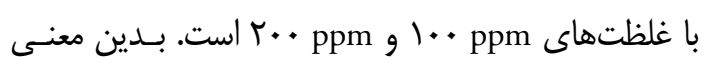
كه اين تيمار قبل و بعد از ييرسازى تغيير شديدى را نشان

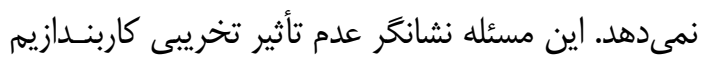

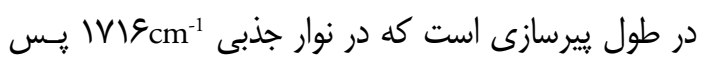
از تيمار در نمونهها ديده مىشود و بيانكر عدم تغييـرات در

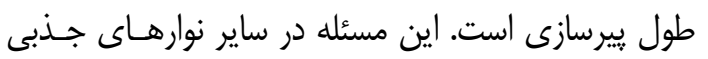
مربوط به اجزاى ساختارى كاغذ نيز وجود داشته و تغييرات

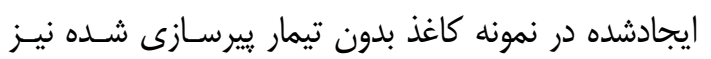

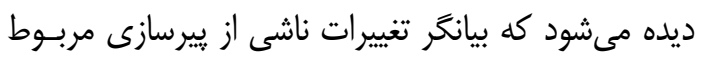

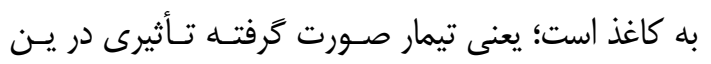
فرآيند نداشته است.

\section{ه- نتيجل}

قارجكشهاى تيوفانات متيل و كاربندازيم كـه هـــر دو از

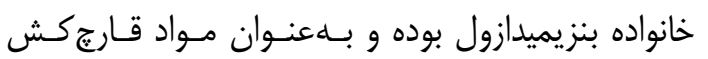

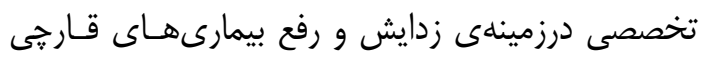

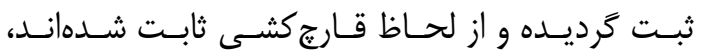
بلهورى كه قدرت تأثير آنها بسيار كَترده بوده و قـادر

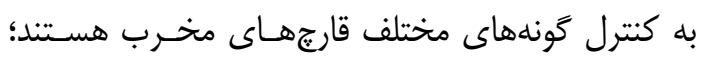

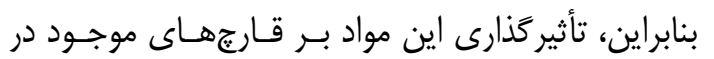

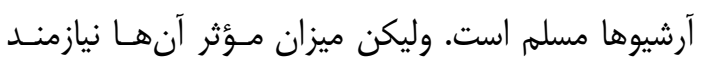




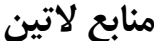

Aboul-Enein, Y., Bunaciu, A. A., Udriștioiu, F. M., \& Tanase, I. G. (2012). Application of microRaman and FT-IR spectroscopy in forensic analysis of questioned documents. Gazi University Journal of Science, 25(2), 371-375.

Adelantado, C., Bello, C., Borrell, A., \& Calvo, M. A. (2005). Evaluation of the antifungal activity of products used for disinfecting documents on paper in archives. Restaurator, 26(4), 235-238.

Bacilkova, B. (2006). Study on the Effect of Butanol Vapours and other Alcohols on Fungi. Restaurator, 27(3), 186-199.

Bollen, G. J. (1972). A comparison of the in vitro antifungal spectra of thiophanates and benomyl. Netherlands Journal of Plant Pathology, 78(2), 55-64.

Ciolacu, D., Kovac, J., \& Kokol, V. (2010). The effect of the cellulose-binding domain from Clostridium cellulovorans on the supramolecular structure of cellulose fibers. Carbohydrate research, 345(5), 621-630.

Courtney, G. F. (1977). Stability of thiophanatemethyl in aqueous dispersion. Pesticide Science, 8(3), 211-213

Cycon, M., Wojcik, M., \& Piotrowska-Seget, Z. (2011). Biodegradation kinetics of the benzimidazole fungicide thiophanate-methyl by bacteria isolated from loamy sand soil. Biodegradation, 22(3), 573-583.

Fabbri, A. A., Ricelli, A., Brasini, S., \& Fanelli, C. (1997). Effect of different antifungals on the control of paper biodeterioration caused by fungi. International biodeterioration \& biodegradation, 39(1), 61-65.

Farag, A., Ebrahim, H., ElMazoudy, R., \& Kadous, E. (2011). Developmental toxicity of fungicide carbendazim in female mice. Birth Defects Research Part B: Developmental and Reproductive Toxicology, 92(2), 122-130.

Garg, K. L. (1995). Use of homoeopathic drugs as antifungal agent for the protection of books and paper materials. In Biodeterioration of cultural property 3: proceedings of the 3 rd international conference on biodeterioration of cultural property, July 4-7, 1995, Bangkok, Thailand (pp. 104-115). Office of Archaeology and National Museums. Conservation Science Division.

Gisi, U., Kuck, K. H., Russell, P. E., \& Lyr, H. (2005). Modern fungicides and antifungal compounds IV. Alton, Hampshire: BCPC.

Gorassini, A., Calvini, P., \& Baldin, A. (2008, June). Fourier Transform Infrared spectroscopy (FTIR) analysis of historic paper documents as a preliminary step for chemometrical analysis. In Atti del Congresso: Multivariate Analysis and Chemometry Applied to Environment and Cultural Heritage, second ed., Ventotene, Italy (pp. 1-4).
دارند و نيز تأثيرات آنها بر گونههاى مختلف قارج مخرب كاغذ، در مجالى ديخر مىتواند صورت گيـرد؛ زيـرا اولـين

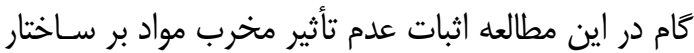
سلولز بود. حال با توجه به نتايج ايجادشـده، بخـش ديخــر مطالعه كه بر تأثير مواد به قارجهاى مخرب اشاره دارد بـا بـا استناد بر نتايج اين يزوهش، قابلاجرا است.

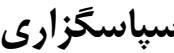

نويسنده بر خود لازم مىدارد از مدير گروه محترم مرمست

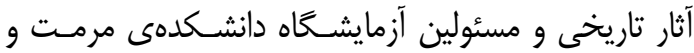

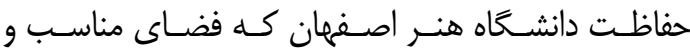

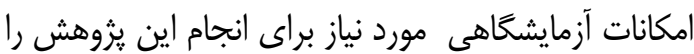
در اختيار اينجانب گذاشتند، تشكر و قدردانى نمايد.

منابع فارسى

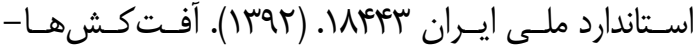

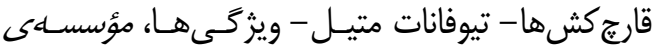

استاندارد و تحقيقات صـنتتى /يسران. ( Institute of

.(Standards and Industrial Research of Iran

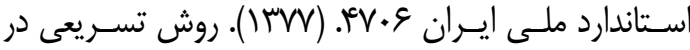

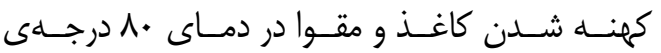

سلسيوس و رطوبت ها درصد، مؤسســهى استاندارد و

تحقيقات صنعتى /يران. ( Institute of Standards and

.Industrial Research of Iran

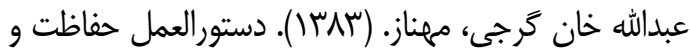

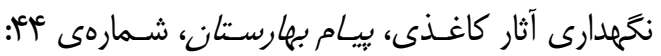
. $1-19$

ميرهكى، فرشـاد، و شـاكرى، عليرضـا. (rqوا). بررسىى

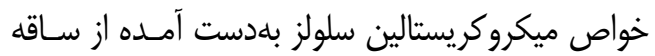
ينبه و يوست كنف، مجلهى صنايع جِوب و كاغذ /يران، سال קهارم، شمار0ى دوم، سז-זr. آريا فر، علىاصغر، سامانيان، كوروس، و افشار يـور، مـريهم.

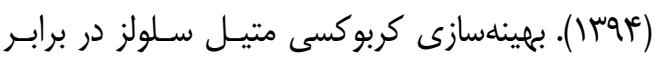
عوامل ميكروار كانيسم با استفاده از نانو ذرات دى ديساكسيد

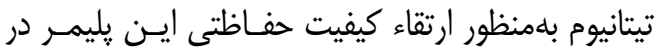

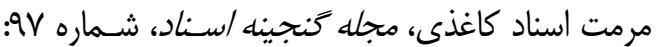
$.1|9-14|$ 
Gutarowska, B., Skora, J., Zduniak, K., \& Rembisz, D. (2012). Analysis of the sensitivity of microorganisms contaminating museums and archives to silver nanoparticles. International Biodeterioration \& Biodegradation, 68, 7-17.

Hajji, L., Boukir, A., Assouik, J., Lakhiari, H., Kerbal, A., Doumenq, P., ... \& De Carvalho, M. L. (2015). Conservation of Moroccan manuscript papers aged 150, 200 and 800years. Analysis by infrared spectroscopy (ATR-FTIR), $\mathrm{X}$-ray diffraction (XRD), and scanning electron microscopy energy dispersive spectrometry (SEM-EDS). Spectrochimica Acta Part A: Molecular and Biomolecular Spectroscopy, 136, 1038-1046.

Hirschfeld, T., Ellner, F., Buschhaus, H., Goßmann, M., \& Büttner, C. (2010). Investigations in the mode of action of thiophanate-methyl in Fusarium spp. Vom Lebensmittel zum Genussmittel-was essen wir morgen, 262-264.

Ibrahim, M., Osman, O., \& Mahmoud, A. A. (2011). Spectroscopic analyses of cellulose and chitosan: FTIR and modeling approach. Journal of Computational and Theoretical Nanoscience, 8(1), 117-123.

Lamberth, C., \& Dinges, J. (Eds). (2012). Bioactive Heterocyclic Compound Classes: Pharmaceuticals. John Wiley \& Sons.

Michaelsen, A., Pinzari, F., Barbabietola, N., \& Piñar, G. (2012). Monitoring the effects of different conservation treatments on paperinfecting fungi. International Biodeterioration \& Biodegradation

Nauha, E., Saxell, H., Nissinen, M., Kolehmainen, E., Schafer, A., \& Schlecker, R. (2009). Polymorphism and versatile solvate formation of thiophanate-methyl. CrystEngComm, 11(11), 2536-2547.

Pesticide residues in food: (2006). toxicological evaluations, sponsored jointly by FAO and WHO, with thesupport of the International Programme on Chemical Safety / Joint Meeting of the FAO Panel of Experts on Pesticide Residues in Food and the Environment and
WHO Core Assessment Group, Rome, Italy, 312 October 2006.

Rakotonirainy, M. S., Fohrer, F., \& Flieder, F. (1999). Research on fungicides for aerial disinfection by thermal fogging in libraries and archives. International biodeterioration \& biodegradation, 44(2), 133-139.

Sanches, N. B., Pedro, R., Diniz, M. F., da Costa Mattos, E., Cassu, S. N., \& Dutra, R. D. C. L. (2013). Infrared spectroscopy applied to materials used as thermal insulation and coatings. Journal of Aerospace Technology and Management, 5(4), 421-430.

Sandahl, M., Mathiasson, L., \& Jönsson, J. A. (2000). Determination of thiophanate-methyl and its metabolites at trace level in spiked natural water using the supported liquid membrane extraction and the microporous membrane liquid-liquid extraction techniques combined on-line with high-performance liquid chromatography. Journal of Chromatography A, 893(1), 123-131.

Sequeira, S., Cabrita, E. J., \& Macedo, M. F. (2012). Antifungals on paper conservation: An overview. International Biodeterioration \& Biodegradation, 74, 67-86.

Van der Kerk, G. J. M. (1973). Chemical and biochemical aspects of systemic fungicides. EPPO Bulletin, 2(10), 5-21.

Velikova, T., Trepova, E., \& Rozen, T. (2011). The use of biocides for the protection of library documents: before and now. Science against microbial pathogens: communicating current research and technological advances $\mathrm{A}$. Méndez-Vilas (Ed.), FORMATEX, 152-159.

Vonk, J., \& Sijpesteijn, A. K. (1971). Methyl benzimidazol-2-ylcarbamate, the fungitoxic principle of thiophanate-methyl. Pesticide Science, 2(4), 160-164.

Weaver-Meyers, P. L., Stolt, W. A., \& Kowaleski, B. (1998). Controlling mold on library materials with chlorine dioxide: an eight-year case study. The Journal of academic librarianship, 24(6), 455-458. 